HELGA BEZERRA GOMES DA SILVA

\title{
Avaliação de fatores preditivos para náusea e vômito no pós- operatório de pacientes oncológicos
}

Tese apresentada à Faculdade de Medicina da Universidade de São Paulo para obtenção do título de Doutor em Ciências.

Área de Concentração: Anestesiologia

Orientador: Prof. Dr. Hazem Adel Ashmawi

(Versão corrigida. Resolução CoPGr 6018/11, de 1 de novembro de 2011. A versão original está disponível na Biblioteca da FMUSP).

São Paulo 
HELGA BEZERRA GOMES DA SILVA

\section{Avaliação de fatores preditivos para náusea e vômito no pós- operatório de pacientes oncológicos}

Tese apresentada à Faculdade de Medicina da Universidade de São Paulo para obtenção do título de Doutor em Ciências.

Área de Concentração: Anestesiologia Orientador: Prof. Dr. Hazem Adel Ashmawi

(Versão corrigida. Resolução CoPGr 6018/11, de 1 de novembro de 2011. A versão original está disponível na Biblioteca da FMUSP).

São Paulo 
Dados Internacionais de Catalogação na Publicação (CIP)

Preparada pela Biblioteca da

Faculdade de Medicina da Universidade de São Paulo

Creprodução autorizada pelo autor

Silva, Helga Bezerra Gomes da

Avaliação de fatores preditivos para náusea e vômito no pós-operatório de

pacientes oncológicos / Helga Bezerra Gomes da Silva . -- São Paulo, 2015.

Tese(doutorado)--Faculdade de Medicina da Universidade de São Paulo.

Programa de Anestesiologia.

Orientador: Hazem Adel Ashmawi.

Descritores: 1.Náusea e vômito pós-operatório 3.Fatores de risco 4.Quimioterapia 5.Anestesia 6.Período pós-operatório 7.Previsões

USP/FM/DBD-406/15 
Dedico esta Tese ao meu marido,

Gabriel Magalhães Nunes Guimarães,

e a nosso primeiro filho,

Arthur Bezerra Guimarães. 


\section{AGRADECIMENTOS}

Ao meu orientador, Prof. Dr. Hazem Adel Ashmawi, por agradável convivência, pelas sugestões e pela oportunidade de contínuo aprendizado e desenvolvimento científico ao seu lado.

À Dra. Angela Maria Sousa, por co-orientar este projeto.

À Faculdade de Medicina da Universidade de São Paulo.

À Coordenadora do Programa de Pós-Graduação em Anestesiologia do Departamento de Anestesiologia da FMUSP, Profa. Dra. Maria José Carmona, pela oportunidade, colaboração e confiança.

Agradeço, enfim, a toda minha família, pelo apoio incondicional e permanente. 
"Paciência e tempo dão mais resultado do que força e raiva."

La Fontaine 
Este trabalho resultou na seguinte publicação:

1- Acta Anaesthesiol Scand. 2015 Oct; 59(9):1145-53. doi: 10.1111/aas.12552.

Does previous chemotherapy induced nausea and vomiting predict postoperative nausea and vomiting?

da Silva HB, Sousa AM, Guimarães GMN, Slullitel A, Ashmawi HA. 


\section{Normatização adotada}

Esta dissertação ou tese está de acordo com as seguintes normas, em vigor no momento desta publicação:

Referências: adaptado de International Committee of Medical Journals Editors (Vancouver).

Universidade de São Paulo. Faculdade de Medicina. Divisão de Biblioteca e Documentação. Guia de apresentação de dissertações, teses e monografias. Elaborado por Anneliese Carneiro da Cunha, Maria Julia de A. L. Freddi, Maria F. Crestana, Marinalva de Souza Aragão, Suely Campos Cardoso, Valéria Vilhena. 3a ed. São Paulo: Divisão de Biblioteca e Documentação; 2011.

Abreviaturas dos títulos dos periódicos de acordo com List of Journals Indexed in Index Medicus. 


\section{Sumário}

Lista de abreviaturas e siglas

Lista de figuras

Lista de tabelas

Resumo

Abstract

1.INTRODUÇÃO

2.MÉTODOS

3.RESULTADOS 16

4.DISCUSSÃO 26

5.CONCLUSÕES 36

6.ANEXO: REGRESSÕES LOGÍSTICAS MÚLTIPLAS 37

7.REFERÊNCIAS BIBLIOGRÁFICAS

APÊNDICE: publicação decorrente desta tese 46 


\section{LISTA DE ABREVIATURAS E SIGLAS}

AAC Área Abaixo da Curva

ACP Analgesia controlada pelo paciente

AIC Do inglês: Akaike information criterion

ASA Do inglês: American Society of Anesthesiologists

BIC Do inglês: Bayesian Information Criterion

CCO Curvas de características operacionais

CMTD Centro Multidisciplinar de Tratamento de Dor

CRAN Do inglês: Comprehensive R Archive Network

Cols Colaboradores

ICESP Instituto do Câncer do Estado de São Paulo

IC Intervalo de Confiança

IMC Índice de Massa Corporal

NVPO Náusea e Vômito Pós-Operatório

NVPQ Náusea e Vômito Pós-Quimioterapia

OR Do inglês: odds ratio

ROC Do inglês: Receiver Operating Curve

USP Universidade de São Paulo 


\section{LISTA DE FIGURAS}

Figura 1 - Fluxograma do estudo

23

Figura 2 - Curvas ROC dos modelos de regressão logística com o critério de APFEL e com o critério de APFEL adicionado da variável NVPQ (APFEL + QT) 24

Figura 3 - Incidência de NVPO de acordo com o critério de APFEL e com o critério de APFEL adicionado da variável NVPQ 


\section{LISTA DE TABELAS}

TABELA 1 - PREVALÊNCIA E DISTRIBUIÇÃO DAS VARIÁVEIS ESTUDADAS. DADOS EM PORCENTAGEM OU VALOR DA MÉDIA COM DESVIO PADRÃO - ICESP ABRIL A MAIO DE 2011

TABELA 2: TIPO DE PROCEDIMENTO CIRÚRGICO E PROBABILIDADE CORRESPONDENTE DE NVPO - ICESP ABRIL A MAIO DE 2011.

TABELA 3 - PREVALÊNCIA DE NÁUSEAS E VÔMITOS PÓS OPERATÓRIOS - ICESP ABRIL A MAIO DE 2011 ..........20

TABELA 4 - PREVALÊNCIA DE NVPO PREVISTA DE ACORDO COM A PRESENÇA DOS FATORES DE RISCO DO CRITÉRIO DE APFEL (PONTUADO DE 0-4) E O OBSERVADO - ICESP ABRIL A MAIO DE 2011 ....................2 20

TABELA 5 - PREVALÊNCIA DO ANTIEMÉTICO PROFILÁTICO PÓS OPERATÓRIO VERSUS CRITÉRIO DE APFEL

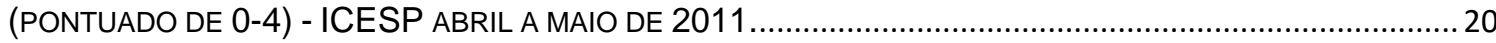

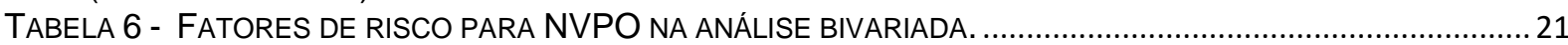

TABELA 7 - ASSOCIAÇÃO ENTRE TIPO DE ANTIEMÉTICO PRESCRITO EM INTERVALOS REGULARES E INCIDÊNCIA DE NÁUSEAS OU VÔMITOS.

TABELA 8 - RESULTADO DA ANÁLISE DA REGRESSÃO MÚLTIPLA LOGÍSTICA DOS 1491 PACIENTES PARA

SELECIONAR QUAL VARIÁVEL QUE ADICIONA AO CRITÉRIO DE APFEL PODER DE PREVISÃO DE NVPO ...22

TABELA 9 - REGRESSÃO LOGÍSTICA DE NÁUSEAS OU VÔMITOS COM O CRITÉRIO DE APFEL. ...............................22

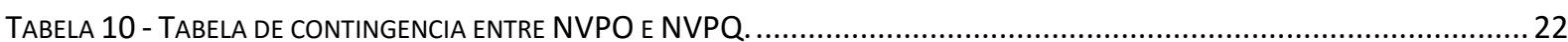

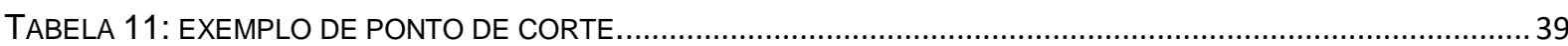




\section{RESUMO}

Silva, HBG. AVALIAÇÃO DE FATORES PREDITIVOS PARA NÁUSEA E VÔMITO NO PÓS-OPERATÓRIO DE PACIENTES ONCOLÓGICOS. 2015. Tese (Doutorado em Ciências) - Faculdade de Medicina da Universidade de São Paulo, São Paulo, Brasil.

Introdução: Náuseas e vômitos (NV) são ainda um desafio problemático no período pós operatório (PO). Modelos preditores, como o critério de Apfel, auxiliam para estratificação do risco dos pacientes e direcionar profilaxias antieméticas. Identificar fatores de risco que possam adicionar informações ao critério de Apfel no paciente oncológico é de extrema importância pela vulnerabilidade à Náusea e Vômito Pósoperatório (NVPO) nesta população. Métodos: foi realizado um estudo retrospectivo de 1500 pacientes oncológicos consecutivos submetidos a cirurgias oncológicas de médio a grande porte entre abril e julho de 2011. NVPO foi avaliada nas primeiras 24 horas de pós-operatório durante a avaliação pós-anestésica pela equipe do Centro Multidisciplinar de Tratamento de Dor (CMTD) do ICESP. Foi preenchido um prontuário eletrônico com todas as variáveis estudadas. A análise de regressão logística múltipla foi realizada para avaliar se qualquer das variáveis poderia adicionar alguma capacidade de previsão para o modelo preditor de Apfel e foram modeladas curvas CCO (curvas características do operadora). As áreas abaixo da curva (AAC) foram utilizados para comparar a capacidade discriminante do modelo para prever os pacientes que vomitaram daqueles que não o fizeram. Resultados: A incidência global de NVPO foi de $26 \%$. Regressões logísticas múltiplas identificaram dois preditores independentes (razão de chances, IC 95\%): pontuação do Apfel $(1,78 ; 1,23-2,63)$ e náuseas e vômitos anteriores induzidos pela quimioterapia $(3,15 ; 1,71-5,9)$, $p$ de Hosmer -Lemeshow $<0,0001$. Náusea e Vômito Pós Quimioterapia (NVPQ) anterior é o indicador mais importante para ser adicionado ao modelo preditor de Apfel nesta população. Conclusão: história de NVPQ deve ser considerada como um forte preditor para NVPO e deve ser adicionado como um fator de risco para NVPO no período préoperatório de pacientes oncológicos.

Descritores: náusea e vômito pós-operatório; fatores de risco; quimioterapia; anestesia; período pós-operatório; previsões. 


\begin{abstract}
Silva, HBG. Assessment of risk factors for postoperative nausea and vomiting in oncological patients. 2015. Thesis (PhD in Sciences) - São Paulo Medical School, University of São Paulo, São Paulo, Brazil.

Background: Postoperative nausea and vomiting (PONV) is still a troublesome problem in the postoperative period. Predictive models as Apfel score help to stratify risk of patients and orientate antiemetic prophylaxis. Identifying risk factors that may add information to Apfel score in oncological patient is of extreme importance due to the vulnerability to PNV in this population. Methods: We conducted a retrospective study of 1500 consecutive patients undergoing intermediate or major cancer surgery between April and July 2011. PONV was assessed in the first 24 hours by Pain Management Team. Electronic medical record with all the studied variables was filled. Multiple logistic regression analysis were performed to assess if any of the variable could add some predictive ability to Apfel's tallying heuristic and a receiver operating characteristic (ROC) curves were modeled. The areas under the curve (AUC) were used to compare the model's discriminating ability for predicting patients who vomited from those who did not. Results: The overall incidence of PONV was $26 \%$. Multiple logistic regressions identified two independent predictors (odds ratio; 95\% Cl): Apfel's score $(1.78 ; 1.23-2.63)$ and previous chemotherapy-induced nausea and vomiting (3.15; 1.71-5.9), Hosmer-Lemeshow's $p<0.0001$. Previous CINV is the most significant predictor to be added to Apfel's heuristic in this population. Conclusions: History of previous CINV should be considered as a strong predictor for PONV and should be added as an additive risk factor for PONV in the preoperative period of oncological surgery.
\end{abstract}

Descriptors: postoperative nausea and vomiting; risk factors; drug therapy; anesthesia; postoperative period; forecasting. 


\section{INTRODUÇÃO}

\subsection{Definição}

Náusea é a sensação desagradável associada à necessidade de vomitar, uma sensação desconfortável subjetiva associada a consciência da necessidade urgente de vomitar. ${ }^{1,2}$ Geralmente, é sentida na porção posterior da garganta e epigástrio e é acompanhada pela perda do tônus gástrico, contrações duodenais e refluxo do conteúdo intestinal no estômago. ${ }^{1}$

Vômito é a expulsão forçada de conteúdo gástrico pela boca que ocorre pela contração sustentada dos músculos abdominais, descida do diafragma e abertura da cárdia gástrica. 1,2

Náuseas e vômitos pós-operatórios (NVPO) são definidos quando esses fenômenos ocorrem até 24 horas após o paciente ser submetido a um procedimento cirúrgico, esta é a padronização para investigação científica. ${ }^{3}$ Essa definição está relacionada com sua associação com estratégias pré-operatórias e transoperatórias para sua prevenção, e também com sua associação forte com fatores anestésicos e cirúrgicos e menor importância dos outros fatores fisiopatológicos possíveis nesse período. Quando o fenômeno ocorre após 24 horas é chamado apenas de náusea, por ter sua fisiopatologia mais complexa e multifatorial.

\subsection{Etiologia}

O reflexo do vômito parece ter origem no centro emético ou centro do vômito e há múltiplas aferências sensórias envolvidas neste reflexo. ${ }^{4}$

O centro do vômito, localizado na formação reticular lateral na medula, recebe aferências da zona quimiorreceptora (assoalho do $4^{\circ}$ ventrículo), aparelho vestibular ou nervo vestibular (VIII nervo craniano), cerebelo, sistema límbico, nervo vago ( $X$ nervo craniano), núcleo do trato solitário e ainda de centros 
corticais superiores. ${ }^{2,5}$ As vias envolvidas no vômito podem ser acionadas por numerosos estímulos que se integram e ativam o centro do vômito. ${ }^{2}$

São vários os tipos de receptores envolvidos na transmissão de impulsos ao centro do vômito: acetilcolínicos muscarínicos, dopaminérgicos (D2), histamínicos $(\mathrm{H} 1)$, opioides, serotoninérgicos $(5-\mathrm{HT} 3)$ e neurocinínicos (NK-1). ${ }^{1}$

Há mecanismos específicos envolvidos neste processo. O nervo vago transmite estímulos sensitivos, principalmente liberando serotonina. Mecanorreceptores e quimiorreceptores no trato gastrointestinal, trato respiratório e sistema cardiovascular também estão envolvidos neste processo. ${ }^{4}$ O nervo vestibular retransmite a entrada do labirinto, primariamente com os neurotransmissores histamina e acetilcolina. ${ }^{4} \mathrm{O}$ sistema límbico parece atuar na resposta de náuseas e vômitos antecipatórios. ${ }^{6}$ A zona quimiorreceptora é exposta ao sangue e fluido cerebrospinal e pode reagir a substâncias plasmáticas incluindo serotonina, dopamina, histamina, acetilcolina, substância $\mathrm{P}$ e adrenalina. ${ }^{7}$ Os fatores metabólicos, que incluem uremia, diabetes mellitus (hipo ou hiperglicemia), distúrbios eletrolíticos (sódio, potássio), desequilíbrios hormonais (estrogênio, progesterona) e gravidez, também podem ativar o centro do vômito. Além disso, há também aferências sensitivas, que incluem a estimulação tátil posterior da faringe, o alongamento, a inflamação ou prejuízo para as vias aéreas. ${ }^{4}$ Outros fatores também contribuem para NVPO incluem desidratação, certos odores, dor, apreensão e medo. ${ }^{1}$ É possível concluir que a cascata etiológica do reflexo de náuseas e vômitos é complexa e inclui múltiplas etiologias.

\subsection{Incidência e consequências}

Apesar da introdução de novos agentes anestésicos com potencial emetogênico reduzido, a incidência de náuseas e vômitos pós-operatórios continua a ser de $30 \%$ a $50 \%$ dos pacientes em geral e até $70 \%$ a $80 \%$ nos pacientes de alto risco. ${ }^{8-10} \mathrm{Em}$ um estudo, após anestesia geral, a incidência de NVPO é de até 30\% quando anestésicos inalatórios são usados sem profilaxia. ${ }^{11}$ 
Além de ser um sintoma desconfortável no pós-operatório, NVPO são também uma das causas mais importantes de insatisfação durante a recuperação da anestesia. $^{12}$ Alguns pacientes consideram mais estressante NVPO do que a própria dor pós-operatória. ${ }^{13}$

NVPO diminuem o conforto e satisfação do paciente, podem provocar efeitos colaterais injustificáveis como desidratação, desequilíbrios eletrolíticos, aspiração pulmonar do conteúdo gástrico, ruptura de esôfago, deiscência de sutura, sangramento e também aumentar os custos hospitalares, por exemplo, com antieméticos para resgate e outros insumos para cuidados com o paciente que vomita, readmissão e prolongamento da internação. ${ }^{14-21}$ NVPO são uma das queixas mais comuns após a cirurgia sob anestesia geral, em conjunto com a dor pós-operatória. ${ }^{14}$

NVPO e suas complicações resultantes são caras para o setor de saúde de todo o mundo, com centenas de milhões de dólares gastos anualmente só nos EUA. ${ }^{22}$ Dado interessante mostrou que pacientes estavam dispostos a pagar uma média de 56 dólares para evitar NVPO; o valor aumentou para US $\$ 73$ e US \$100 em pacientes que já experimentaram náuseas ou vômitos pósoperatórios, respectivamente. ${ }^{23}$

Prevenção de NVPO é uma grande preocupação para os pacientes antes de cirurgias. Em estudo com 220 pacientes, sobre o que mais preocupava os pacientes no período pós operatório, as contribuições relativas dos diferentes fatores foram: (1) (ausência de) NVPO, 49\%; (2) (ausência de) dor pósoperatória, 27\%; (3) (ausência de) sedação pós-operatória, 13\%; (4) nenhum gasto extra ser cobrado, de $11 \%{ }^{24}$ Os autores concluíram que os pacientes estariam dispostos a aceitar outras complicações e mesmo custos pessoais adicionais para atenuar ou prevenir NVPO. ${ }^{24}$

Em outro estudo semelhante foi proposto aos pacientes gastarem uma quantia hipotética de 100 dólares para evitar alguns efeitos colaterais da anestesia. $^{25}$ Os resultados mostraram que os pacientes estariam dispostos a 
despender, em média, uma quantia superior para evitar vômitos (18 dólares) e náuseas (12 dólares), comparada a evitar dor pós-operatória (17 dólares) ou tremor (8 dólares). ${ }^{25}$

Este contexto se agrava em hospitais oncológicos onde os pacientes são expostos repetidamente a situações com grande potencial emetogênico como cirurgias, radio ou quimioterapias e outros fármacos para o controle da própria doença ou sintomas envolvidos como a dor.

De fato, é importante ressaltar que a qualidade dos serviços de saúde pode ser melhorada pela elucidação das preferências dos pacientes e com a personalização dos cuidados a atender as necessidades dos mesmos. NVPO podem levar a complicações médicas graves mesmo em ambiente hospitalar moderno e o impacto na qualidade de vida e custo de cuidados de saúde não são insignificantes. ${ }^{25}$

\subsection{Prevenção de NVPO}

NVPO é um fenômeno multifatorial que pode ser desencadeado pela associação de condições emetogênicas com a susceptibilidade individual. Apesar de profilaxia antiemética ter seus benefícios, a profilaxia indiscriminada e inespecífica de rotina é geralmente inapropriada pelos custos e riscos envolvidos. O número de pacientes necessários a serem tratados (NNT) para prevenir um paciente de sofrer NVPO é cerca de $\operatorname{cinco}^{26}$ quando a taxa de episódios de NVPO é relativamente alta, porém, pode haver aumento de custos desnecessários se os pacientes de baixo risco receberem medicações profiláticas em comparação com a estratégia de tratamento antiemético de resgate. ${ }^{27}$

Atualmente não é aceitável negligenciar o potencial da profilaxia antiemética. NVPO podem acarretar sérias consequências inclusive com comprometimento súbito respiratório. 27,28 
A avaliação dos fatores de risco para NVPO tornou-se mais do que apenas um simples exercício acadêmico e pode fundamentar as recomendações baseadas em evidências para o manejo de NVPO. ${ }^{29}$

Estratégias adaptadas a riscos devem ser usadas uma vez que pacientes de alto risco podem se beneficiar muito com a profilaxia e os pacientes de baixo risco podem ter apenas efeitos colaterais, pois a redução do risco absoluto é predominantemente relacionada ao risco inicial dos pacientes. ${ }^{2,10,30}$

Nem todos pacientes cirúrgicos são beneficiados com profilaxia antiemética, sendo importante a identificação dos pacientes que estão em maior risco. Usar os critérios objetivos para avaliação de risco disponíveis pode levar ao uso mais eficiente da terapia antiemética preventiva e melhor custobenefício. ${ }^{31}$ Mesmo que a profilaxia antiemética não possa eliminar o risco de NVPO, ela pode reduzir significativamente sua incidência. ${ }^{31}$ Diretrizes baseadas em dados clínicos fornecem ferramentas de referências para o tratamento de pacientes que serão submetidos a procedimentos cirúrgicos e têm riscos moderados ou altos para NVPO.

Devido a esses argumentos, com objetivo de avaliar o risco basal dos pacientes, modelos simples para classificação de risco para NVPO foram desenvolvidos e são usados atualmente ${ }^{32-34}$ apesar da complexidade da etiologia de NVPO.

\subsubsection{Histórico dos Modelos Preditores}

Diretrizes clínicas incluem cada vez mais modelos preditores ou escores de risco para auxiliar os médicos em seu processo de decisão. ${ }^{35,36} \mathrm{Um}$ modelo é a representação simplificada de algum problema ou situação da vida real destinado a ilustrar certos aspectos do problema sem se ater a todos os detalhes. ${ }^{37} \mathrm{O}$ crescimento do uso de modelos de previsão pode ser justificado por sua objetividade em modelar interações complexas para prever o risco de 
um paciente, em contraste com o julgamento clínico do médico que é tipicamente heurístico.

Não raro, mais de um modelo pode descrever um mesmo fenômeno, haja vista que cada pesquisador tem a liberdade de modelar o fenômeno seguindo a metodologia que julgar mais adequada. ${ }^{37}$

Modelos preditores de risco para NVPO são geralmente baseados nos resultados de análises de regressões logísticas múltiplas. ${ }^{38}$ Recomenda-se inclusive que esses modelos sejam usados em ensaios clínicos para comparação do risco entre os grupos. ${ }^{39}$ Eles também podem auxiliar gestores de serviços hospitalares a avaliar se a incidência de NVPO é maior que a esperada ou não e, consequentemente, se os custos envolvidos neste processo podem ser reduzidos.

Fatores de risco para NVPO têm sido descritos na literatura desde o final de 1800.40 Tradicionalmente a investigação era focada em um fator potencial a cada vez, sem o controle das outras variáveis. ${ }^{17,41}$ Em estudos com estes inconvenientes, a verdadeira influência do fator de risco investigado não fica definida. Pesquisas mais recentes sobre os fatores de risco para NVPO iniciaram no início de 1990, com publicações dos primeiros estudos que se ativeram a identificar simultaneamente múltiplos fatores de risco e para isso utilizaram modelos de regressão logística múltipla para controlar a vasta variedade de variáveis. ${ }^{17,41}$

Até o momento, numerosos modelos preditivos para NVPO foram desenvolvidos, mas muitos com limitado poder de discriminação $27,38,39$ à exceção do modelo do Escore de $\mathrm{Apfe}^{33}$, que é um dos modelos mais utilizados e conhecidos e de fácil aplicabilidade clínica. De fato, os modelos preditores simplificados fornecem melhores propriedades discriminativas e regulatórias comparada ao modelos de maior complexidade. ${ }^{27}$ Esta característica de ser simplificado favorece, portanto, o seu uso prático e acessível na rotina diária hospitalar. 
É importante ter em mente que ao selecionarmos modelos é preciso ter conhecimento que não existem modelos verdadeiros, mas apenas modelos aproximados da realidade que, causam perda de informações. ${ }^{37}$ Deste modo, é necessário fazer a seleção do "melhor" modelo, dentre aqueles que foram ajustados, para explicar o fenômeno sob estudo. ${ }^{37}$

\subsubsection{Validação do modelo preditor de Apfel}

A primeira publicação de Apfel e seu grupo sobre a investigação dos fatores de risco para NVPO e modelos preditores foi em 1998, quando sua proposta original envolveu apenas cirurgia de amígdalas e ouvido. Foram identificados fatores de risco relevantes para seu modelo preditor: sexo feminino, não tabagismo, histórico prévio de cinetose ou NVPO, longo tempo de duração da anestesia e idade jovem. ${ }^{42}$

Ainda em 1998, Apfel e colaboradores publicaram outro estudo comparando o seu modelo preditor inicial e a proposta de um novo modelo porém agora envolvendo outros tipos de cirurgias e concluíram que o seu modelo inicial era válido para outros tipos de cirurgias. ${ }^{43}$

Em seguida, em 1999, Apfel e colaboradores compararam o poder preditor de dois modelos preditivos diferentes em centros diferentes e concluíram que o seu modelo preditor teve validação quando aplicado em outro centro e pôde ser simplificado sem perda significativa do seu poder de discriminação. ${ }^{33}$

O modelo de Apfel simplificado avaliou a presença de quatro fatores de risco para NVPO que são: sexo feminino, não tabagismo, histórico prévio de cinetose ou NVPO e uso de opioides no pós operatório. ${ }^{33}$ Se nenhum, um, dois, três ou quatro destes fatores de risco estiverem presentes, a incidência de NVPO é $10 \%, 21 \%, 39 \%, 61 \%$ ou $79 \%$ respectivamente. ${ }^{33}$ Os autores orientam o uso de alguma estratégia antiemética profilático se o paciente apresentar pelo menos dois destes fatores de risco. ${ }^{33}$ 
Há na literatura publicações que evidenciam a validade externa do modelo de Apfel simplificado. Ao serem comparados seis modelos preditivos em relação ao seu poder de discriminação e praticabilidade com seus diferentes números de parâmetros: Apfel (com 4 parâmetros), Koivuranta (com 5 parâmetros), Palazzo (com 5 parâmetros), Scholz (com 9 parâmetros) Sinclair (com 12 parâmetros) e Gan (com 14 parâmetros), o modelo preditor de Apfel simplificado foi o que teve melhor poder de discriminação. ${ }^{27}$

Weilbach e colaboradores mostraram que o modelo preditor de Apfel simplificado é uma ferramenta simples e válida para a estratificação de pacientes com alto risco de NVPO. ${ }^{44}$ Outro estudo comparou o modelo preditor de Apfel simplificado com o modelo preditor de Sinclair $^{45}$ (que adiciona aos quatro parâmetros do modelo de Apfel as variáveis duração da anestesia, tipo de anestesia e tipo de cirurgia) e mostrou que o modelo de Apfel simplificado apresentou propriedades discriminativas favoráveis para a previsão de NVPO e portanto foi orientada a implementação deste modelo na prática clínica bem como na triagem contínua para profilaxia antiemética. ${ }^{46}$

Sigaut e colaboradores demostraram que uma estratégia educacional com base em um forte encorajamento à sistemática medição e registro pré-operatória da pontuação simplificada de Apfel, associada às respectivas diretrizes, é eficiente para diminuir a incidência de NVPO em uma população de adultos pacientes cirúrgicos. ${ }^{47}$ Estes resultados fornecem uma forma simples e eficiente de hipótese de trabalho para melhorar a gestão de NVPO em unidades que atendam pós operatório de pacientes adultos. ${ }^{47}$

\subsection{Fatores de risco para NVPO}

Fatores de risco, de acordo com os modelos preditores para NVPO, podem estar relacionados com características intrínsecas dos pacientes, com o procedimento cirúrgico realizado ou com a técnica anestésica que foi 
utilizada. 2,48 Além disso, há crescente interesse sobre o papel que a genética pode desempenhar na probabilidade de desenvolver NVPO. 49

\subsubsection{Fatores de risco intrínsecos do paciente}

Fatores de risco específicos do paciente mais estudados são: sexo, histórico de tabagismo ou não, histórico de cinetose, histórico de NVPO prévios, idade, índice de massa corpórea (IMC) e estado físico pela ASA (American Society of Anesthesiologists). Destes, de acordo com estudo de revisão sistemática com regressão logística múltipla, os que tiveram maior relevância foram: sexo feminino (OR 2,57), seguido por histórico de NVPO prévios ou cinetose (OR 2,09), não tabagismo (OR 1,82) e idade (OR 0,88 por década). ${ }^{48}$ IMC e estado físico pela ASA não se mostraram estatisticamente significantes. ${ }^{48}$

\subsubsection{Fatores de risco relacionados à técnica anestésica}

Dos cinco fatores de risco mais estudados, relacionados à anestesia, a partir de estudo de revisão sistemática com regressão logística múltipla, o uso de anestésicos voláteis foi o mais forte preditor (OR 1,82), seguindo-se a duração da anestesia (OR 1,46 $\mathrm{h}^{-1}$ ), uso de opioides no pós-operatório (OR 1,39) e o uso de óxido nitroso (OR 1,45). ${ }^{48}$ Uso de opioides no intra-operatório não foi um preditor estatisticamente significativo. ${ }^{48}$

\subsubsection{Fatores de risco relacionados ao procedimento cirúrgico}

Em relação aos tipos de cirurgias, alguns procedimentos cirúrgicos foram tradicionalmente associados a maior incidência de NVPO (correção de estrabismo, cirurgia otorrinolaringológica, cirurgia ginecológica, cirurgia para ombro e cirurgia laparoscópica). ${ }^{45}$ Porém, de acordo com estudo de revisão sistemática com regressão logística múltipla, os procedimentos cirúrgicos que tiveram maior associação com NVPO foram: colecistectomia, que foi o mais forte preditor (OR 1,90), seguido de procedimentos laparoscópicos (OR 1,37) e cirurgias ginecológicas (OR 1,24).48 Por outro lado, os modelos preditivos de 
risco para NVPO que incluem o tipo de cirurgia não fornecem maior valor preditivo, quando comparados com os modelos simplificados. ${ }^{27,46}$

\subsubsection{Fatores de risco genéticos}

Há associações consistentes com polimorfismos de nucleotídeo único que ocorrem em genes envolvendo receptores neurais de sinalização e transmissão do sistema de náuseas e vômitos. ${ }^{49}$ Polimorfismo do nucleotídeo único do receptor de serotonina tipo 5-HT3 (subunidade A e B), receptores muscarínicos tipo 3 , e receptores $\mu$ opioides estão associados com NVPO. ${ }^{50-57}$ Associação entre o polimorfismo do nucleotídeo único da catecol-metil-transferase e NVPO pode estar relacionada à função desta enzima na degradação de catecolaminas e potencial mudança na sinalização neuronal. ${ }^{49,52}$ Polimorfismos em nucleotídeo de receptores dopaminérgicos tipo 2 também estão relacionados a NVPO ${ }^{58} \mathrm{e}$ acredita-se que receptores adrenérgicos alfa-2 desempenham função central no circuito emético. ${ }^{59,60}$ Polimorfismos de nucleotídeo único nos genes de HTR3B, COMT e CHRM3 podem estar associados com a variabilidade em náuseas e vómitos entre pacientes com câncer que estão em uso crônico de opioides. ${ }^{53}$

De acordo com a diversidade de fatores de riscos potencialmente envolvidos, há a necessidade de melhorar o modelo preditor de Apfel para NVPO para o paciente oncológico. Há necessidade de um modelo com poder discriminatório comparável ao modelo de Apfel que auxilie na tomada de futuras decisões, de acordo com o preconizado pela medicina baseada em evidências, e que resulte na melhora da qualidade do processo perioperatório em hospitais oncológicos.

\subsection{OBJETIVO}

Este estudo teve como objetivo avaliar se há variáveis que aumentam significantemente o poder de discriminação do modelo preditor de Apfel para NVPO no paciente oncológico. 


\section{Métodos}

\subsection{Tipo de Estudo}

Estudo observacional retrospectivo de fatores de risco para incidência de náuseas e vômitos nas primeiras 24 horas de pacientes oncológicos.

\subsection{Seleção dos pacientes e origem dos dados}

Após aprovação pelo Comitê de Ética e Pesquisa da Faculdade de Medicina da Universidade de São Paulo (CEP-FMUSP), foi realizado estudo de 1500 pacientes cirúrgicos consecutivos entre primeiro de abril de 2011 e 31 de julho de 2011 do Instituto do Câncer do Estado de São Paulo (ICESP). O Termo de Consentimento Livre e Esclarecido (TCLE) não foi aplicado, de acordo com a autorização de dispensa do mesmo pelo CEP-FMUSP com a justificativa de ser um trabalho de obtenção de dados em prontuário.

\subsection{Origem dos dados}

Os dados foram obtidos retrospectivamente de prontuários eletrônicos padronizados preenchidos sistematicamente e prospectivamente como parte da rotina da equipe do Centro Multidisciplinar de Tratamento de Dor (CMTD) do ICESP. A padronização dos formulários do prontuário eletrônico tem finalidade administrativa e facilita a assistência clínica.

O formulário eletrônico selecionado para a pesquisa foi preenchido no período pós-operatório imediato de acordo com a rotina padrão dos pacientes cirúrgicos atendidos e acompanhado pela equipe do Centro Multidisciplinar de Tratamento de Dor do ICESP, na qual são avaliados todos pacientes oncológicos submetidos a cirurgias de médio e grande porte. 


\subsection{Critérios de Inclusão}

Os critérios de inclusão foram pacientes oncológicos adultos (maiores que 18 anos de idade), submetidos a cirurgias eletivas de médio ou grande porte e acompanhados de rotina pelo Centro Multidisciplinar de Tratamento de Dor do ICESP. (Observação: pacientes submetidos a cirurgias de pequeno porte geralmente não necessitam do acompanhamento rotineiro da equipe do CMTD).

\subsection{Critérios de Exclusão}

Os critérios de exclusão para preenchimento do formulário eletrônico padronizado que a equipe do CMTD usa rotineiramente foram: pacientes que não compreendessem ou não se comunicassem em português, gestantes, pacientes com déficit cognitivo ou distúrbio de consciência (confusão mental, agitação ou delirium que não permitisse a comunicação, pacientes sedados ou intubados). Para a pesquisa foram excluídos os dados de pacientes cujo formulário eletrônico estava incompleto e pacientes em óbito ou admissão inesperada em Unidade de Terapia Intensiva (UTI) antes de completar 24 horas do pós-operatório.

\subsection{Desfecho estudado}

O desfecho estudado foi a ocorrência de náuseas ou vômitos (presença ou ausência), nas primeiras 24 h pós-operatórias. A ocorrência de náuseas ou vômitos pós operatórios (NVPO) foi definida para os objetivos da análise como qualquer manifestação de náusea e/ou vômito ocorrendo nas primeiras 24 horas de acordo com: informação do paciente durante entrevista, náusea ou vômito registrados no prontuário do paciente, informação direta pelo enfermeiro do dia responsável pelo paciente em prontuário eletrônico e administração de doses de resgate de antieméticos além do antiemético prescrito de rotina, registrados em 
prontuário eletrônico. Náuseas ou vômitos não estavam disponíveis em intensidade, apenas em padrão dicotômico (sim ou não) nesta base de dados.

\subsection{Fatores de risco estudados}

Os fatores de risco estudados por leitura de prontuário eletrônico foram: idade (variável numérica discreta, em anos), sexo (masculino ou feminino), procedimento cirúrgico realizado (variável categórica), técnica anestésica realizada (variável categórica), critério de Apfel (variável ordinal com valores entre zero e quatro, definida pelo número de fatores de risco: sexo feminino, não tabagismo, história de NVPO ou cinetose prévios e planejamento de usar opioides no pós-operatório), administração de opioide em neuroeixo (sim ou não), uso crônico de opioides (sim ou não), via de administração de opioide pós operatório (peridural, sistêmico ou ambos), tipo de analgesia pós operatória (se analgesia controlada pelo paciente - ACP ou não), medicação antiemética prescrita de rotina (variável categórica), se usou medicação antiemética de resgate prescrita (sim ou não), tipo de antiemético administrado (variável categórica), o relato (após ser questionado durante avaliação de rotina da equipe do CMTD e registrado em prontuário eletrônico) do paciente sobre episódios de náuseas e vômitos durante sessões prévias de quimioterapia (sim ou não).

\subsection{Preenchimento do formulário de avaliação padronizado pelo CMTD}

\subsubsection{Momento e local da avaliação}

Cada paciente foi entrevistado por um anestesiologista ou enfermeira treinada da equipe do Centro Multidisciplinar de Tratamento de Dor nas primeiras 24 horas do período pós-operatório para o preenchimento do formulário próprio de avaliação de uso rotineiro e sistematizado pelo CMTD e registrado em prontuário eletrônico. A entrevista ocorreu na ala cirúrgica ou na enfermaria, de acordo com o caso. 


\subsubsection{Coleta dos dados da pesquisa}

As variáveis de interesse a serem estudadas foram compiladas do prontuário eletrônico para formulário próprio.

\subsection{Redução de viés}

Não houve padronização da técnica anestésica utilizada (anestesia geral, neuraxial ou a combinação das duas), como também do antiemético profilático utilizado. Estes procedimentos foram realizados a critério dos médicos responsáveis em cada caso ou de acordo com as normas de rotina da instituição. Apesar da maior parte dos pacientes ter recebido algum tipo de antiemético no período intraoperatório (principalmente dexametasona e/ou ondansetrona ou ambos) estes dados não foram considerados para a análise.

\subsection{Análise estatística}

A análise estatística foi realizada utilizando o pacote estatístico $R$ da CRAN (Comprehensive R Network) com extensão pROC. ${ }^{61}$ A presença ou não de NVPO foi definida como única variável dependente para todos os testes.

Foi realizada inicialmente, como forma de triagem, uma sequência de análises bivariadas. Isso significou que foi testada a hipótese nula da associação de cada possível preditor com NVPO isoladamente. Para a análise de cada fator de risco, o teste exato de Fisher foi utilizado para testar variáveis dicotômicas, o teste de $U$ de Mann-Whitney para variáveis ordinais e a regressão logística simples para variáveis categóricas e numéricas.

As variáveis cuja a estatística $p$ da associação bivariada foram menores que $5 \%$ foram selecionadas para a etapa da análise multivariada. Realizamos uma regressão logística múltipla com seleção anterógrada como análise multivariada. 


\subsubsection{Aplicação da regressão logística múltipla}

Após a fase de triagem com análises bivariadas, uma análise de regressão múltipla foi realizada para avaliar quais os melhores preditores para NVPO para a geração de um modelo de previsão. Foi usada a técnica de seleção anterógrada dos preditores usando $p<5 \%$ como critério de entrada no modelo e $p>5 \%$ como critério de remoção das variáveis do modelo. Para evitar o super ajustamento, o critério de informação de Akaike (AIC - Akaike Information Criterion) foi usado para selecionar os modelos de regressão logística múltipla. O critério de Apfel simplificado foi usado como uma das variáveis independentes, pois o mesmo apresenta poder preditivo semelhante ao do modelo original. ${ }^{33}$

Como não se tratavam de modelos de séries temporais, ${ }^{37} 0$ critério de informação bayesiano (BIC - Bayesian Information Criterion) teve desempenho similar ao critério de informação de Akaike e critério de informação de Akaike corrigido para selecionar os modelos de regressão múltipla. Foi escolhido portanto o critério de informação de Akaike para este fim, porém, tanto BIC quanto AIC selecionaram os mesmos modelos em uma análise paralela que realizamos.

Além do modelo obtido neste estudo (com as variáveis testadas) foi gerado também um modelo de regressão simples para prever NVPO usando apenas o critério simplificado de Apfel como preditor. Após, com o objetivo de estimar o poder de discriminação entre esses modelos de regressão logística (comparar o modelo com o critério simplificado de Apfel com o modelo gerado neste estudo) foram modeladas curvas ROC (receiver operating characteristic), também traduzida por alguns autores brasileiros como curvas CCO (curva de características operacionais). As áreas abaixo da curva ROC (AAC) foram calculadas como descrito por DeLong. ${ }^{62}$ Os intervalos de confiança de 95\% das áreas abaixo da curva (AAC) e testes de hipóteses foram realizados por métodos não-paramétricos de DeLong. ${ }^{62} \mathrm{O}$ teste Hosmer-Lemeshow foi usado para avaliar a significância global dos modelos. 
Detalhes sobre as regressões logísticas múltiplas e sobre curvas ROC encontram-se em anexo.

\section{Resultados}

Foram incluídos 1491 pacientes na análise final do estudo. Nove pacientes foram excluídos por dados incompletos (faltava a variável NVPO, essencial para o estudo) como mostra o fluxograma do estudo na Figura 1. A prevalência e distribuição das variáveis estudadas é mostrada na Tabela 1. A distribuição do tipo de cirurgia é mostrada na Tabela 2.

A incidência de NVPO foi 26\% (Tabela 3). A distribuição da prevalência de NVPO de acordo com o previsto pelos fatores de risco do critério de Apfel e o observado na população estudada é mostrada na Tabela 1. A distribuição da prevalência dos antieméticos profiláticos mais frequentemente usados de rotina e fatores de risco para NVPO segundo critério de Apfel é mostrada na Tabela 5.

A triagem das variáveis na análise bivariada mostrou que os fatores de risco significantes $(p<0,05)$ para NVPO foram: critério de Apfel, sexo feminino, histórico de NVPO ou cinetose prévios, não tabagismo, técnica de analgesia pós operatória utilizada (analgesia sistêmica intermitente, analgesia controlada pelo paciente venosa ou peridural ou dose única de morfina peridural), histórico de náuseas ou vômitos pós quimioterapia (NVPQ) e idade (Tabela 6).

Não houve associação entre o tipo de antiemético prescrito de rotina no pós-operatório e NVPO, quando não considerada a estratificação de risco pelo critério de Apfel (Tabela 7).

Após a triagem das variáveis e aplicação da regressão múltipla logística com os fatores de risco significantes encontrados, apenas a variável NVPQ foi incluída como fator de risco preditor adicional a NVPO ao ser considerado o critério de Apfel (Tabela 8). Com esta variável adicionada ao critério simplificado 
de Apfel foi gerado um novo modelo preditor de NVPO. A seleção das variáveis como possíveis preditores adicionais ao critério de Apfel foi realizada por meio de seleção anterógrada com $p<5 \%$ como critério para inclusão da variável no modelo e $p>5 \%$ como critério de remoção das variáveis e o critério de informação de Akaike para a seleção do modelo.

O modelo de regressão simples logística apenas com o critério de Apfel como preditor é mostrado na Tabela 9.

As áreas abaixo das curvas ROC modeladas (AAC), mostradas na Figura 2, foram respectivamente 0,64 e 0,70 para o modelo com o critério de Apfel (pontuação entre 0-4) e o modelo com o critério de Apfel com adição da variável NVPQ (pontuação entre 0-5), e esta diferença foi estatisticamente significante $(\mathrm{p}=0,049)$. Os intervalos de confiança de $95 \%$ das áreas abaixo da curva e testes de hipóteses foram realizadas por métodos não-paramétricos de DeLong. ${ }^{62} \mathrm{O}$ teste Hosmer-Lemeshow apresentou $p<0,0001$ para ambos os modelos.

A incidência de NVPO de acordo com o critério de Apfel e com o critério de Apfel adicionado a variável NVPQ é mostrada na Figura 3. A variável NVPQ foi importante fator de risco (ver detalhes na tabela de contingência $2 \times 2$, Tabela 10). 
Tabela 1 - Prevalência e distribuição das variáveis estudadas. Dados em porcentagem ou valor da média com desvio padrão - ICESP abril a maio de 2011.

Variável

Prevalência/

Incidência ou

média (DP)

\begin{tabular}{|c|c|}
\hline Sexo & \\
\hline Masculino & $47 \%$ \\
\hline Feminino & $52,9 \%$ \\
\hline Idade (anos) & $58,19(13,6)$ \\
\hline Analgesia pós operatória & \\
\hline - ACP Peridural & $15,8 \%$ \\
\hline - $\quad$ ACP Venosa & $11,3 \%$ \\
\hline - Morfina peridural (dose única) & $1,8 \%$ \\
\hline - Analgesia venosa intermitente & $61,6 \%$ \\
\hline - Nenhuma & $7 \%$ \\
\hline - Dados faltantes & $2,2 \%$ \\
\hline Anestesia & \\
\hline Geral & $37,6 \%$ \\
\hline Peridural com geral & $48,9 \%$ \\
\hline Subaracnoidea & $2,5 \%$ \\
\hline Subaracnoidea com geral & $5,8 \%$ \\
\hline Outras & $5,2 \%$ \\
\hline Critério de Apfel Simplificado & \\
\hline - 0 & $4 \%$ \\
\hline - 1 & $22,2 \%$ \\
\hline - 2 & $37,3 \%$ \\
\hline - 3 & $25,1 \%$ \\
\hline - 4 & $4,4 \%$ \\
\hline - Dados faltantes & $6,7 \%$ \\
\hline Antiemético profilático & $67,6 \%$ \\
\hline Quimioterapia prévia & $18 \%$ \\
\hline $\begin{array}{l}\text { Antecedente de náusea ou vômito pós } \\
\text { quimioterapia prévia em toda a amostra }\end{array}$ & $7,8 \%$ \\
\hline $\begin{array}{l}\text { Antecedente de náusea ou vômito pós } \\
\text { quimioterapia em quem fez quimioterapia }\end{array}$ & $43,2 \%$ \\
\hline Cinetose ou NVPO prévios & $6,6 \%$ \\
\hline Não tabagismo & $50,6 \%$ \\
\hline Usuário crônico de opioides & $10,9 \%$ \\
\hline Usou antiemético de resgate & $20,8 \%$ \\
\hline Opioides no pós operatório & $60,3 \%$ \\
\hline
\end{tabular}

ACP: Analgesia Controlada pelo Paciente 
Tabela 2: Tipo de procedimento cirúrgico e probabilidade correspondente de NVPO ICESP abril a maio de 2011.

\begin{tabular}{|c|c|c|c|c|c|}
\hline Procedimento & $\begin{array}{l}\text { Proporção } \\
\%\end{array}$ & $\begin{array}{l}\text { NVPO } \\
\%\end{array}$ & $\begin{array}{l}\text { Feminino } \\
\%\end{array}$ & $\begin{array}{l}\text { Razão de } \\
\text { chances }\end{array}$ & $\mathrm{p}^{*}$ \\
\hline Prostatectomia & 13,4 & 22,4 & 0 & 0,8 & 1 \\
\hline Mastectomia & 10,7 & 38 & 96 & 1,9 & 0,02 \\
\hline Nefrectomia & 6,4 & 28 & 31 & 1,1 & 1 \\
\hline Cirurgia plástica & 6,4 & 13 & 70 & 0,4 & 0,2 \\
\hline Cabeça e pescoço & 6,0 & 19 & 30 & 0,6 & 1 \\
\hline Histerectomia & 5,6 & 29 & 100 & 1,2 & 1 \\
\hline Retossigmoidectomia & 4,6 & 32 & 49 & 1,3 & 1 \\
\hline Setorectomia mamária & 4,5 & 40 & 100 & 2 & 0,55 \\
\hline $\begin{array}{l}\text { Exerese de tumor por } \\
\text { toracotomia }\end{array}$ & 4,0 & 20 & 48 & 0,7 & 1 \\
\hline Cistectomia & 3,7 & 19 & 35 & 0,7 & 1 \\
\hline Hepatectomia & 2,9 & 34 & 45 & 1,5 & 1 \\
\hline Laparotomia exploradora & 2,9 & 31 & 63 & 1,3 & 1 \\
\hline Colectomia & 2,6 & 15 & 47 & 0,5 & 1 \\
\hline Artrodese de coluna & 2,6 & 17 & 30 & 0,6 & 1 \\
\hline Gastrectomia & 2,4 & 11 & 50 & 0,3 & 1 \\
\hline Ooforectomia & 1,9 & 37 & 100 & 1,8 & 1 \\
\hline Linfadenectomia extensa & 1,7 & 23 & 50 & 0,8 & 1 \\
\hline Amputação de perna & 1,4 & 4 & 40 & 0,1 & 1 \\
\hline Duodenopancreatectomia & 1,2 & 31 & 52 & 1,3 & 1 \\
\hline Esofagectomia & 1,2 & 5 & 44 & 0,2 & 1 \\
\hline Tireoidectomia & 1,1 & 41 & 70 & 2 & 1 \\
\hline Peritonectomia & 1,1 & 12 & 68 & 0,5 & 1 \\
\hline Citorredução (debulking) & 0,93 & 35 & 100 & 1,6 & 1 \\
\hline Fixação de múltiplos ossos & 0,87 & 15 & 46 & 0,5 & 1 \\
\hline Biliodigestiva & 0,7 & 45 & 54 & 2,4 & 1 \\
\hline Outros & 9,2 & 29 & 47 & NA & 1 \\
\hline
\end{tabular}

${ }^{*}$ corrigido para múltiplos testes com o método de Bonferroni. 
Tabela 3 - Prevalência de náuseas e vômitos pós operatórios - ICESP abril a maio de 2011.

\begin{tabular}{ll}
\hline Variável & Prevalência \\
\hline Náuseas & $26 \%$ \\
Vômitos & $15,7 \%$ \\
\hline
\end{tabular}

Tabela 4 - Prevalência de NVPO prevista de acordo com a presença dos fatores de risco do critério de Apfel (pontuado de 0-4) e o observado - ICESP abril a maio de 2011.

\begin{tabular}{llllll}
\hline Pontuação & 0 & 1 & 2 & 3 & 4 \\
\hline Critério de Apfel & $10 \%$ & $21 \%$ & $39 \%$ & $61 \%$ & $79 \%$ \\
Observado & $10 \%$ & $17 \%$ & $21 \%$ & $36 \%$ & $62 \%$ \\
\hline
\end{tabular}

Tabela 5 - Prevalência do antiemético profilático pós operatório versus critério de Apfel (pontuado de 0-4) - ICESP abril a maio de 2011.

\begin{tabular}{lrrlll} 
Critério de Apfel & 0 & 1 & 2 & 3 & 4 \\
\hline Ondansetrona & $52 \%$ & $49 \%$ & $58 \%$ & $62 \%$ & $69 \%$ \\
Metoclopramida & $24 \%$ & $30 \%$ & $22 \%$ & $17 \%$ & $16 \%$ \\
Ondansetrona e & $4 \%$ & $7 \%$ & $8 \%$ & $3 \%$ & $3 \%$ \\
Metoclopramida & & & & & \\
\hline
\end{tabular}


Tabela 6 - Fatores de risco para NVPO na análise bivariada.

\begin{tabular}{lll}
\hline Variável & Incidência de NVPO & \\
\hline Critério de Apfel Simplificado & & \\
0 & 0,1 & \\
1 & 0,17 & $<0,0001$ \\
2 & 0,21 & $<0,0001$ \\
3 & 0,36 & $<0,0001$ \\
4 & 0,62 & $<0,0001$ \\
Sexo & & \\
Feminino & 0,31 & $<0,0001$ \\
Masculino & 0,19 & \\
Cinetose ou NVPO prévios & & \\
Sim & 0,47 & $<0,0001$ \\
Não & 0,23 & \\
Tabagismo & & \\
Sim & 0,15 & 0,0001 \\
Não & 0,28 & \\
Histórico de NVPQ & 0,42 & $<0,0001$ \\
Sim & 0,22 & \\
Não & & \\
Analgesia pós operatória & 0,30 & $<0,0001$ \\
ACP Peridural & 0,14 & $<0,0001$ \\
ACP Venosa & 0,29 & $<0,001$ \\
Morfina peridural (dose & & \\
única) & 0,24 & 0,002 \\
Analgesia sistêmica & & \\
intermitente & $-0,03$ & \\
Idade & & \\
Por ano & de Mann-Whitney e a regressão logística simples. \\
Teste exato de Fisher, teste de U &
\end{tabular}

Tabela 7 - Associação entre tipo de antiemético prescrito em intervalos regulares e incidência de náuseas ou vômitos.

\begin{tabular}{lll}
\hline Antiemético regular & Razão de chances (IC95\%) & $\mathrm{p}^{*}$ \\
\hline Ondansetrona & $1,10(0,83$ a 1,44$)$ & 0,49 \\
Metoclopramida & $1,01(0,72$ a 1,40$)$ & 0,93
\end{tabular}

* Teste Exato de Fisher 
Tabela 8 - Resultado da análise da regressão múltipla logística dos 1491 pacientes para selecionar qual variável que adiciona ao critério de Apfel poder de previsão de NVPO.

\begin{tabular}{lll}
\hline Variável & $\begin{array}{l}\text { Coeficiente } \\
\text { beta }\end{array}$ & $\mathrm{p}$ \\
\hline Critério de Apfel & 0,63 & $<0,0001$ \\
Náuseas ou Vômitos Pós Quimioterapia & 1,08 & $<0,0001$ \\
(NVPQ) & $-2,9$ & $<0,0001$ \\
Intercepto &
\end{tabular}

Tabela 9 - Regressão logística de náuseas ou vômitos com o critério de Apfel simplificado.

\begin{tabular}{lll}
\hline Variável & Coeficiente beta & $\mathrm{p}$ \\
\hline Intercepto & $-2,58$ & $<0,001$ \\
Critério de Apfel & 0,6431 & $<0,001$ \\
\hline
\end{tabular}

AIC: 936,9 BIC 946,4

Tabela 10 - Tabela de contingencia entre NVPO e NVPQ.

NVPO

$\begin{array}{lccc}\text { NVPQ } & \text { Sim } & \text { Não } & \text { Total } \\ \text { Sim } & 113 & 155 & \mathbf{2 6 8} \\ \text { Não } & 275 & 948 & \mathbf{1 2 2 3} \\ \text { Total } & \mathbf{3 8 8} & \mathbf{1 1 0 3} & \end{array}$

$\bar{p}<0,0001$, Teste exato de Fisher. Razão de chances $=2,51(1,88-3,34)$. 


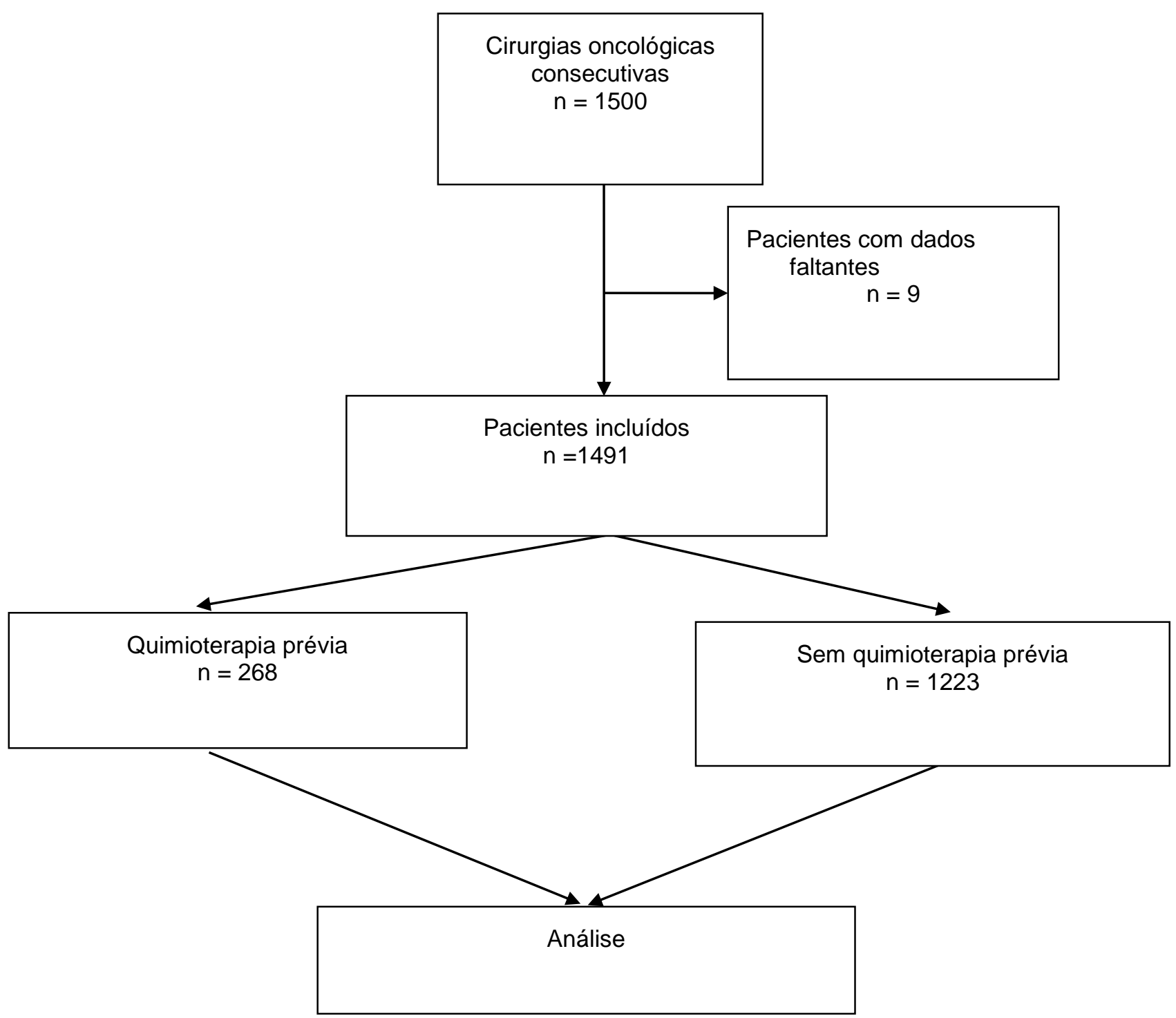

Figura 1: Fluxograma do estudo. 


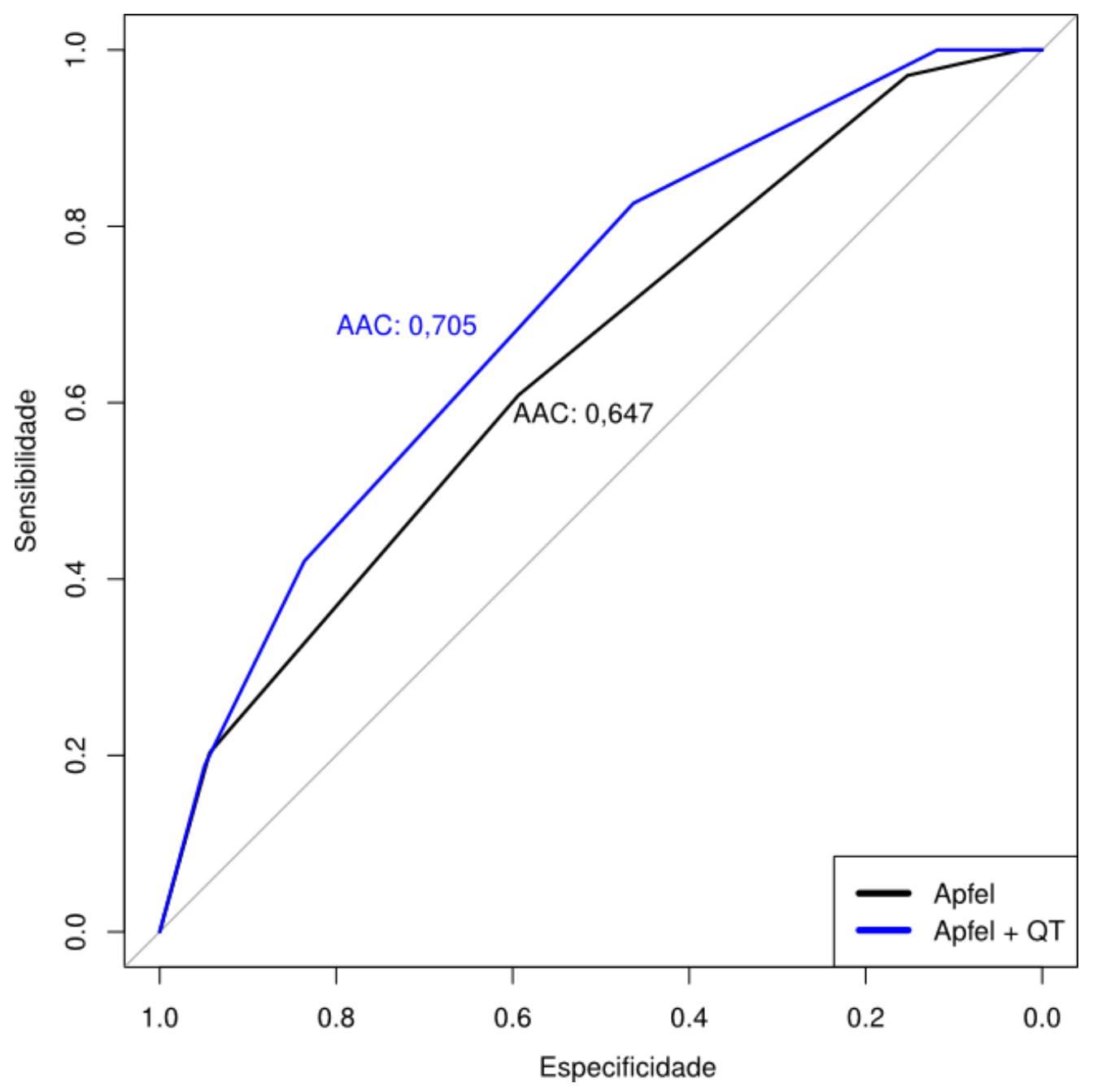

Figura 2: Curvas ROC dos modelos de regressão logística com o critério de Apfel e com o critério de Apfel adicionado a variável NVPQ (Apfel + QT). 


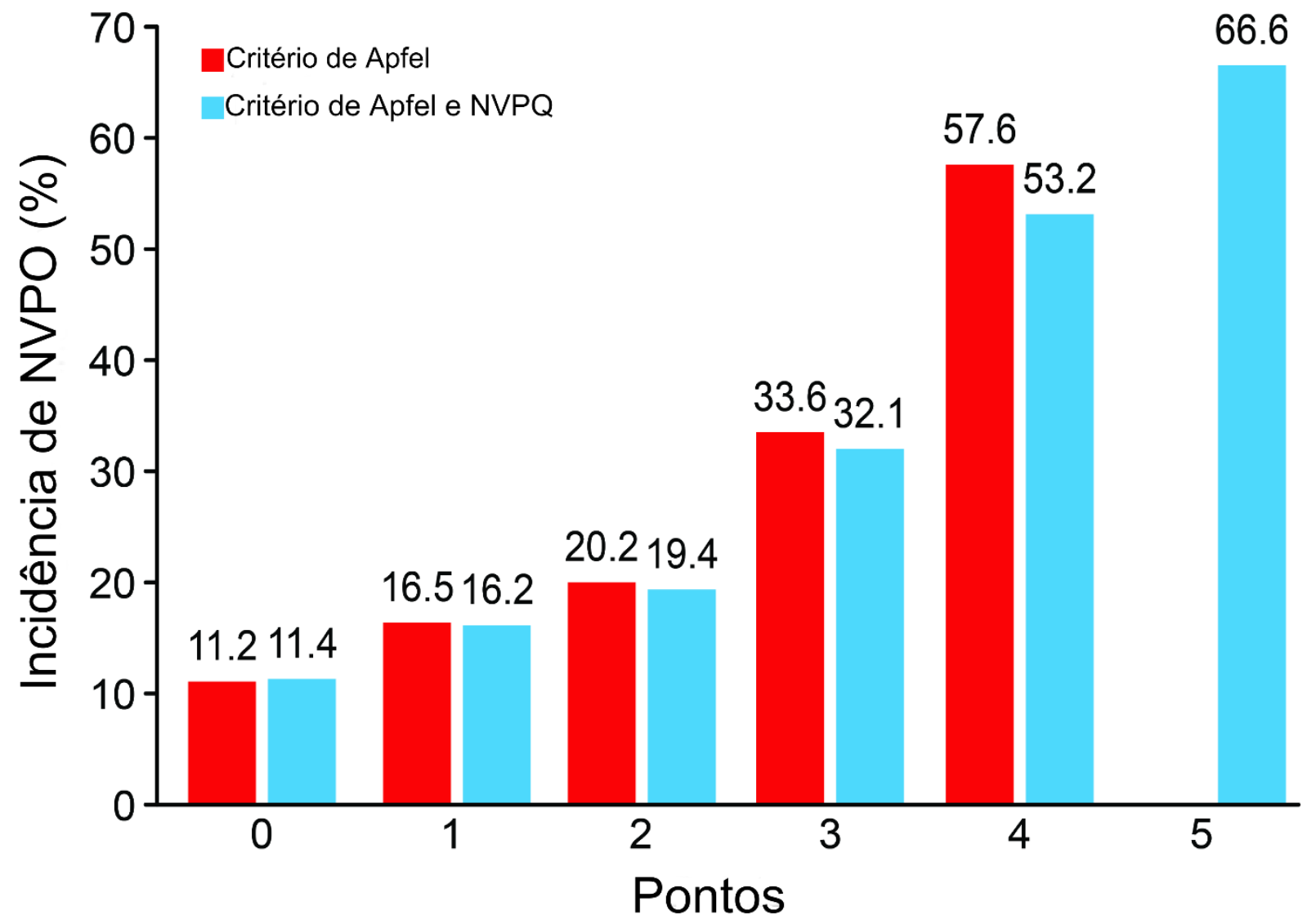

Figura 3: Incidência de NVPO de acordo com o critério de Apfel e com o critério de Apfel adicionado a variável NVPQ. 


\section{Discussão}

É importante destacar que este estudo foi realizado no Instituto do Câncer do Estado de São Paulo (ICESP), um hospital terciário, universitário, de acesso público, especializado em oncologia.

Os medicamentos antieméticos no pós-operatório foram prescritos de rotina a critério da equipe cirúrgica para os pacientes e todos registrados no prontuário eletrônico do serviço. Estudar a incidência de NVPO nesse contexto diminui o viés de baixa validade externa que acontece nos estudos em que se tenta prever a incidência em populações muito específicas como aquelas que não foram expostas a antieméticos ou a determinadas técnicas anestésicas. No estudo de Apfel foram estudados apenas pacientes não expostos a antieméticos. ${ }^{33} \mathrm{~A}$ validade externa, ou seja, a aplicabilidade da evidência do estudo de Apfel é comprometida pelo fato de que os pacientes são rotineiramente expostos a antieméticos profiláticos. $O$ objetivo neste estudo foi obter uma avaliação que considerasse estes fatores de confusão e os compensasse com a análise estatística multivariada.

Ao compararmos as variáveis usadas no modelo de Apfel às variáveis testadas neste estudo, respeitando o mesmo tipo de análise utilizada para formular seu modelo preditor e usando análise de regressões logísticas múltiplas com adição passo a passo, identificamos que a variável NVPQ adicionou poder ao modelo preditor de Apfel. A Tabela 10 fornece mais detalhes sobre a associação entre NVPQ e NVPO (OR 2,51, IC95\% 1,8 a 3,3).

A área abaixo da curva ROC do modelo preditor de Apfel adicionado com a variável NVPQ foi superior a área abaixo da curva ROC do modelo de Apfel isolado que foram respectivamente 0,705 e 0,647 ( $p<0,005)$ (Figura 2). Este tipo de investigação sobre o poder de discriminação entre propostas de modelos de previsão de risco de NVPO é descrito na literatura na qual a análise empregada 
é a comparação das áreas abaixo das curvas ROC entre os respectivos modelos. $3,33,43,46,63$

Neste caso, as curvas ROC são vantajosas para estudar o poder de discriminação de modelos porque elas não dependem da prevalência do desfecho estudado na população. Se, por exemplo, diferentemente o parâmetro acurácia fosse usado para comparar o modelo, ele seria enviesado porque depende da prevalência de NVPO na população estudada.

Outra questão importante são, como visto na Tabela 8 e Tabela 9, os coeficientes $\beta$ gerados do critério de Apfel nas duas fórmulas obtidas do modelo novo formulado com a variável NVPQ e do modelo de Apfel isolado apresentam valores muito próximos (respectivamente 0,63 e 0,64), sugerindo que a variável NVPQ é independente e que não existe colinearidade desta variável no modelo novo gerado aumentando, portando, a relevância deste achado.

É importante ressaltar que realizamos o trabalho de acordo com algumas orientações de estudo sobre preditores de NVPO proposto por $\mathrm{Apfel}^{3} \mathrm{como}^{\mathrm{de}}$ não ser repetido apenas o que já vem sendo testado, com listagem de inúmeras variáveis, mas focar em alguma variável de interesse que possa ser usada na prática clínica por meio de preditores heurísticos, de acordo com o próprio critério de Apfel simplificado. No caso, identificamos a variável NVPQ.

O critério de Apfel e colaboradores ${ }^{14}$, embora originalmente baseado em uma análise de regressão logística, foi simplificado para uma soma de número de preditores presentes, que ignora ponderação do risco de cada fator (coeficientes $\beta$ ), com o objetivo de tornar mais fácil e rápida sua aplicação. ${ }^{64}$ Esses modelos simplificados de modelos complexos são definidos como heurísticas cuja finalidade é tornar mais prática sua aplicação. ${ }^{64}$ Ou seja, heurística é um método ou processo criado com o objetivo de encontrar soluções para um problema. É um procedimento simplificador (embora não simplista) que, em face de questões difíceis envolve a substituição destas por outras de resolução mais fácil a fim de encontrar respostas viáveis, ainda que imperfeitas. 
Apesar do novo modelo ser muito mais simples, Apfel mostrou que seu poder preditivo era semelhante ao do modelo original ${ }^{33}$ e atualmente é um dos critérios validados mais utilizados.

Por outro lado, é de bom senso, na realização de estudos sobre náuseas e vômitos pós operatórios, controlar todos os potenciais fatores de confusão empregados, como por exemplo a técnica anestésica e medicações usadas. ${ }^{3}$

Nestas circunstâncias, porém, pode-se haver limitação quanto à validade externa destes estudos principalmente se as condições especificadas aplicadas no estudo não são usadas cotidianamente. ${ }^{3}$ Isso significa que, embora haja maior validade interna nestes estudos, o seu poder de discriminação pode não ser tão bom na prática diária. Neste estudo, não houve controle de alguns possíveis fatores de confusão (técnica anestésica ou medicações usadas) pois foi realizado em situações que ilustram a rotina diária do serviço.

Ao avaliarmos o poder de discriminação do critério de Apfel isolado neste estudo identificamos que foi inferior a alguns estudos prévios ${ }^{14,38,46}$, mas semelhante a outros estudos validados. ${ }^{34,65}$ Isto corrobora que o critério de Apfel é válido para a nossa prática diária, porém o fato da área abaixo da curva ROC ser de 0,64 pode significar que há necessidade de melhorá-lo para a população oncológica e para alguns autores modelos com áreas menores que 0,7 são insuficientes para guiar a profilaxia antiemética. ${ }^{39} \mathrm{Um}$ dos motivos pelo qual a AAC do critério de Apfel foi menor neste estudo pode ser a menor incidência de cinetose ou NVPO prévios que foi de $6,6 \%($ Tabela 1) comparado a aproximadamente de $60 \%, 31 \%, 23 \%$ e $18,5 \%$, em estudos anteriores. ${ }^{33,38,46,65}$

Em relação aos fatores de risco significantes para NVPO na análise bivariada, identificamos variáveis semellhantes a estudos anteriores que são critério de Apfel, sexo feminino, histórico de NVPO ou cinetose prévios, não tabagismo, idade jovem (Tabela 6). ${ }^{33} \mathrm{~A}$ técnica de analgesia pós operatória utilizada (analgesia sistêmica intermitente, analgesia controlada pelo paciente venosa ou peridural ou dose única de morfina peridural) também foi significante 
e pode ser explicado pelo fato dessas técnicas analgésicas envolverem o uso de opioides em suas composições. A programação do uso de opioides no pós operatório é fator de risco para NVPO descrito na literatura, sendo um dos componentes do critério de Apfel. ${ }^{33}$ Lembrando que a análise bivariada apresenta o potencial de identificar em um primeiro momento as variáveis que são associadas ou não a NVPO, nesta associação pode haver variáveis que apresentam relação de colinearidade, ou seja, variáveis que na verdade estão associadas a outras variáveis também relacionadas e não estão interligadas, necessariamente, de forma direta a variável em questão estudada, no caso, NVPO. Para separar somente as variáveis associadas diretamente a variável NVPO é necessária a utilização de análise multivariada como realizada posteriormente neste trabalho.

Ao avaliarmos o tipo de procedimento cirúrgico e incidência de NVPO (Tabela 2) observamos que houve diferença estatisticamente significante na análise bivariada apenas nas mastectomias. Porém esta diferença não se manteve na análise multivariada. Uma das possíveis justificativas é que $96 \%$ das mastectomias foram feitas em mulheres ou a possibilidade de esta associação ser um falso positivo porque foram feitas múltiplas análises.

Outra questão é o fato que ao compararmos o modelo original preditor de NVPO do critério de Apfel de acordo com a presença dos fatores de risco (pontuados de 0 a 4) à incidência de NVPO observada na população estudada (Tabela 4), observamos que para pontuação maior que 1, NVPO ocorreu em uma prevalência menor que o esperado por Apfel, ${ }^{33} \mathrm{com}$ diferenças maiores para as pontuações entre 2 e 3. As incidências de NVPO previstas por Apfel são de 10\%, 21\%, 39\%, 61\% e 79\% nas pontuações 0, 1, 2, 3 e 4 respectivamente. As incidências de NVPO observadas na população estudada foram de 10\%, 17\%, $21 \%, 36 \%$ e $62 \%$, de acordo com a utilização dos critérios de Apfel nas pontuações 0, 1, 2, 3 e 4 respectivamente. 
Consideram-se as categorias de risco de acordo com a pontuação de Apfel, de 0 ou 1 como baixo risco para NVPO, pontuação de 2 ou 3 como risco moderado e pontuação de 4 como alto risco. ${ }^{31}$

No atual trabalho, os resultados estão fortemente relacionados ao uso de antieméticos no período perioperatório, no qual os antieméticos profiláticos foram administrados a maior parte dos pacientes, sem padronização de estratificação por riscos para NVPO. Inclusive observamos na Tabela 5 que apenas 3\% dos pacientes com risco segundo critério de Apfel de 4 (alto) receberam dois antieméticos profiláticos contra $7 \%$ e $8 \%$ dos pacientes com risco segundo critério de Apfel de 1 e 2 ( baixo e moderado) respectivamente.

Assim, a profilaxia de rotina com os antieméticos ondansetrona ou metoclopramida reduziu a incidência de NVPO em pacientes de médio ou alto risco de acordo com o critério de Apfel. Entretanto, observamos que os pacientes nos dois extremos da curva de risco ( 0 ou 4 ) receberam antieméticos profiláticos além do que é recomendado ou em quantidades insuficientes respectivamente.

Evidenciamos, portanto, a própria falta de estratificação de riscos e protocolos estabelecidos no seviço, problema também relatado em estudo prévio com 192 hospitais suiços, no qual a maior parte da terapia para NVPO foi prescrita individualmente sem uma política formal ou consenso claro sobre responsabilidade de tratamento. ${ }^{66}$

Há um estudo que mostrou o impacto da implementação de recomendações profiláticas para para NVPO associado um modelo preditor de risco para NVPO no pré-operatório que resultou em diminuição da incidência de NVPO particularmente em pacientes de alto risco seguindo recomendações deste modelo. No estudo houve aumento na prescrição de antieméticos de acordo com o risco para profilaxia para NVPO, comparado ao que era feito rotineiramente, e foi evidenciado que a profilaxia dependente do risco reduziu a incidência de NVPO principalmente nos pacientes de alto risco. ${ }^{67}$ 
De modo diferente, outro estudo mostrou que a implementação de um modelo preditor para NVPO sem estar acoplado a um sistema de recomendações terapêuticas não reduziu a incidência de NVPO apesar do aumento da prescrição pelos anestesiologistas de antieméticos em pacientes de alto risco. 68

Importante lembrar que, como todos medicamentos, antieméticos têm efeitos colaterais e custos adicionais. Estes efeitos adversos variam em gravidade e podem ser desde leve cefaléia, hiperglicemia, sepse a prolongamento significatico no intervalo QTC (que pode ser, raramente, associados à parada cardíaca). ${ }^{31,69}$ Há inclusive relato de morte de paciente que recebeu ondansetrona na emergência ${ }^{70}$ e outro relato de bradicardia intensa durante a incisão e drenagem de abscesso. ${ }^{71}$ Isto pode justificar certa relutância na administração de polifarmácia potencialmente desnecessária atualmente e um modelo de previsão ajudaria a alcançar uma relação melhor em se tratando de risco-benefício. ${ }^{67}$

De acordo com os consensos sobre o manejo de NVPO quando se avaliam as indicações da profilaxia antiemética, ela é raramente justificada em pacientes de baixo risco, pacientes com risco moderado podem beneficiar de uma única intervenção, e múltiplas intervenções devem ser reservadas para pacientes de alto risco, ${ }^{31,72}$ ou seja, o risco basal do paciente é o principal determinante da efetividade da intervenção de profilaxia antiemética. ${ }^{31,72}$

Isto mostra que neste estudo não foi necessário usar a correção da amostra pelo escore de propensão. O escore de propensão está relacionado a ferramenta utilizada para amenizar o viés de confusão por indicação, que pode existir nos estudos observacionais em que os pacientes por estarem em extremos de maior risco, por exemplo, receberiam maior número de intervenções ou cuidados automaticamente. ${ }^{73}$

Em relação a incidência de NVPO de acordo com o critério de Apfel e com o critério de Apfel adicionado a variável NVPQ (Figura 3), podemos observar que 
nas pontuações de 1 a 4 a incidência de NVPO em porcentagem foi menor com a aplicação do modelo de Apfel adicionado a variável NVPQ comparado ao modelo de Apfel isoladamente que foi de : 16,2\%, 19,4\%, 32,1\%, 53,2\% contra $16,5 \%, 20,2 \%, 33,6 \%$ e $57,6 \%$ respectivamente.

Este fenômeno se justifica pelo fato que quando distribuímos o mesmo número de pacientes (mesma população estudada) entre 5 categorias (pontuadas de 0 a 4) como no modelo de Apfel e entre 6 categorias (pontuadas de 0 a 5) no caso do modelo de Apfel adicionado a variável NVPQ ocorre uma diluição com redução da incidência de pacientes entre as categorias do modelo com maior número de pontuação.

Ao identificarmos a variável NVPQ potencializando o critério de Apfel podemos questionar algumas hipóteses relacionadas. Em relação a etiologia, náuseas e vômitos pós operatórios (NVPO) é um fenômeno multifatorial que pode ser desencadeado por múltiplas vias de receptores periféricos, centrais ou em ambos os locais ${ }^{74}$, assim como NVPQ (náuseas e vômitos pós quimioterapia) também tem vários fatores envolvidos. ${ }^{75}$

O risco de NVPQ está relacionado com idade jovem, pacientes que apresentam expectativa prévia negativa a quimioterapia devido a experiências de náuseas prévias com tratamento (náuseas antecipatórias), sexo feminino, assim como ocorre no caso de NVPO e sobretudo a emetogenicidade de um determinado agente quimioterápico que é o fator predominante para a previsão NVPQ. ${ }^{75} \mathrm{O}$ consumo de grande quantidade de bebidas alcoólicas previamente seria um fator de proteção. ${ }^{75}$ Há também mecanismos genéticos que podem estar relacionados como o polimorfismo na subunidade do gene HTR3C do receptor de serotonina que é relacionado ao maior risco de NVPQ pós quimioterapia com antraciclina. ${ }^{55,76}$

O risco de NVPO está principalmente relacionado ao sexo feminino, histórico de náuseas ou vômitos prévios a cirurgias ou cinetose, uso de opioides no pós operatório e não tabagismo entre outros fatores. No presente estudo, a 
história anterior de NVPQ foi determinada como fator preditivo para NVPO, independentemente do regime de quimioterapia ou antiemético utilizado, apesar de sexo feminino ser fator preditivo em ambas situações. Assim, a questão de ser um potencial fator de risco para NVPO o fato do paciente ter uma história anterior de NVPQ ainda não havia sido estabelecida.

Por outro lado, há na literatura estudo que mostrou uma relação mais forte entre os pacientes que não vomitaram após cirurgia e, posteriormente, quando submetidos ao tratamento quimioterápico adjuvante, não vomitaram pós quimioterapia comparado aos pacientes que vomitaram em ambas situações na mesma ordem cronológica. ${ }^{77}$ Sugerindo que certos pacientes, ao invés de terem propensão a náuseas e vômitos, na verdade possuem de algum modo proteção contra este indesejável efeito colateral. ${ }^{77}$ Poderia se pensar, neste caso, na existência de grupos de pacientes que se enquadrariam com o comportamento de "não vomitadores" ou "vomitadores".

Em relação aos mecanismos que podem estar envolvidos no potencial fator de risco de NVPQ prévio para NVPO há algumas hipóteses que podem ser questionadas como o fato da memória da experiência negativa deste fenômeno gerar futuras condições de emetogenicidade. Esta situação é descrita pelo reflexo de condicionamento de Pavlov $^{40}$ no qual ocorre náuseas e vômitos antecipatórios a quimioterapia após experiências prévias. ${ }^{40}$

Não se sabe exatamente quais os mecanismos fisiológicos estão envolvidos na náusea e vômito antecipatórios, sabe-se que o tronco cerebral, o núcleo vestibulocerebelar e amígdala estão implicados no desenvolvimento da êmese. ${ }^{40}$ Acredita-se que haja uma ligação entre os sistemas psicológico, neurológico e fisiológico no aprendizado condicionado de resposta de náuseas ou vômitos a quimioterapia no qual cerca de $25 \%$ dos pacientes desenvolvem náusea ou vômito antecipatório após o quarto ciclo de tratamento. ${ }^{40,78,79} \mathrm{O}$ risco disto ocorrer tende a aumentar com o número de ciclos recebidos e os sintomas podem persistir por longo tempo após o término da quimioterapia. ${ }^{80}$ 
Este estudo apresenta algumas limitações. Não foi investigado o histórico de náuseas ou vômitos antecipatórios ou quantificado o número de sessões quimioterápicas dentre os pacientes que apresentaram náuseas ou vômitos pós quimioterapia previamente e não foram registrados os possíveis efeitos adversos de antieméticos utilizados. ${ }^{3}$

Houve grande variabilidade de tipo de procedimentos cirúrgicos envolvidos, apesar de todos serem de médio ou grande porte como visto na distribuição por especialidade cirúrgica na Tabela 2.

Não houve a distinção em relação aos períodos que ocorreram o fenômeno de NVPO estudado (precoce de 0 a 2 horas do pós operatório ou tardio de 2 a 24 horas do pós operatório). ${ }^{3}$ Idealmente seria registrar o horário de cada episódio de NVPO para correlacionar com as causas como por exemplo NVPO precoce está relacionado com uso de inalatórios. ${ }^{3}$ Isto também permitiria fazer testes capazes de detalhar o curso de ação de antieméticos utilizados. ${ }^{3}$ Porém realizamos a incidência cumulativa de NVPO nas primeiras 24 horas é válida para investigações sobre NVPO. ${ }^{3}$

Náusea ou vômito são indiscutivelmente desfechos ruins e potencialmente deletérios à qualidade das intervenções terapêuticas. Quanto maior nossa capacidade de previsão ou suspeição de que um indivíduo apresenta maior susceptibilidade ou não a esses fenômenos, maior atenção e uso de opções de intervenções profiláticas antieméticas ou técnicas anestésicas com menor efeito emético poderão ser direcionados aos pacientes de maior risco. Com a melhora da discriminação dos pacientes em risco para NVPO será possível o direcionamento dos tratamentos de acordo com as necessidades, sem incorrer no aumento de custos desnecessários ou potenciais efeitos adversos do uso indiscriminado de vários antieméticos profiláticos.

Esse contexto é agravado no paciente oncológico, que é um paciente diferente, não só pela gravidade de sua doença ou fenômenos patológicos envolvidos, mas porque se encontra em uma situação de luta constante pela 
vida e onde muitas das vezes seus tratamentos envolvem múltiplos procedimentos como cirurgias, radio ou quimioterapias e outros fármacos para o controle da própria doença, da dor ou dos próprios efeitos adversos. Ainda neste contexto, soma-se o medo ou sofrimento real de ser submetido a constantes situações difíceis e de suportar inclusive os episódios de náuseas e vômitos pós operatórios que podem, dentre outros efeitos deletérios, potencializar a dor aguda no pós operatório.

O desenvolvimento de critério de Apfel para a população oncológica a ser submetida a anestesia é um grande avanço. O uso de quimioterapia préoperatória é um fato comum nesta população. A utilização de critério de risco específico para náuseas e vômitos pós-operatórios e cirurgia nesta população poderá facilitar a adoção de medidas de prevenção e tratamento mais eficientes no futuro.

A realização de trabalhos prospectivos utilizando o modelo preditor aqui desenvolvido é importante para confirmação dos dados obtidos nesta tese. Deve ficar claro que não se pode negar que quando há relevância estatística isto não significa necessariamente a prova de um efeito. Como qualquer resultado encontrado utilizando o método científico, ele é aceito enquanto sobreviver a experimentações posteriores que poderão confirmar ou refutar este resultado e pode ser útil para a criação de uma hipótese posteriori que precisa de confirmação em estudos adicionais. 


\section{Conclusões}

Este trabalho permitiu:

1. A identificação que história de NVPQ anteriores pode ser considerada como um forte preditor para NVPO e pode ser adicionada como um fator de risco para NVPO no período préoperatório de pacientes oncológicos.

2. A geração de um novo modelo preditor para NVPO em pacientes oncológicos, para a amostra estudada, com a adição da variável NVPQ ao critério de Apfel. 


\section{Anexo: regressões logísticas múltiplas}

A regressão é um modelo matemático. Ela é uma equação em que de um lado da igualdade está a variável dependente (aquela a ser prevista) e do outro lado cada um dos preditores multiplicados por um coeficiente. Se por exemplo queremos prever o peso de uma criança entre 2 e 8 anos de idade quando sabemos apenas sua idade o modelo seria:

$$
\text { peso }=10+2 \text { idade } \quad \text { Equação } 1
$$

Neste modelo, idade é um preditor, 2 é o coeficiente da variável idade e o número que não multiplica nenhuma variável (10 no exemplo) é chamado intercepto. O intercepto e esses coeficientes são calculados pelo pacote estatístico como a média do valor da variável dependente na amostra estudada.

O fato de uma regressão ser logística significa que a variável dependente é dicotômica e que o resultado da soma do outro lado da equação será um número entre 0 e 1 . Este resultado representa a probabilidade da variável dependente ter o valor a ser previsto (por exemplo de sexo ser igual a feminino). Um artifício matemático para que o resultado da soma esteja entre 0 e 1 é usar o exponencial da soma como resultado da equação. Considere um modelo de regressão logística para prever NVPO cujo preditor seja o critério de Apfel, como no trabalho original de Apfel, sendo os coeficientes chamados de $\beta$. A equação da propabilidade de NVPO de acordo com o modelo de regressão logística múltipla será:

$$
p(N V P O)=e^{\beta_{0}+\beta_{1} \text { Apfel }} \quad \text { Equação } 2
$$

Comparando a equação 2 com a equação 1 nota-se que $\beta_{0}$ da equação 2 equivale ao intercepto da equação 1 e que $\beta_{1}$ equivale ao coeficiente da variável Apfel. Se o resultado do lado direito da equação for, por exemplo, 0,8 então a probabilidade do paciente vomitar será $80 \%$. 
Para que uma regressão logística seja múltipla é necessário que seja feita a soma de todos os preditores multiplicados por seus respectivos coeficientes. Por exemplo para prever NVPO considerando o critério de Apfel e Quimioterapia, o modelo seria:

$$
p(N V P O)=e^{\beta_{0}+\beta_{1} \text { Apfel+ } \beta_{2} \text { Quimioterapia }} \quad \text { Equação } 3
$$

Note que os coeficientes $\beta$ representam o impacto da variável preditora sobre a variável prevista. Se por exemplo, na equação $3, \beta_{2}$ for maior que $\beta_{1}$, quimioterapia tem impacto maior sobre a probabilidade de NVPO que Apfel.

A técnica de regressão múltipla requer um critério para decidir quais variáveis irão fazer parte do modelo. Variáveis que não adicionam informação relevante ao modelo são um problema porque superestimam o poder total de previsão, logo devem ser eliminadas ou nem mesmo adicionadas. As técnicas de seleção de variáveis das regressões múltiplas têm como objetivo eliminar estas variáveis.

São 3 as principais técnicas de seleção: anterógrada, retrógrada ou passo-a-passo. As três técnicas podem resultar exatamente no mesmo modelo. Se mais de um modelo for obtido, o modelo obtido pela seleção anterógrada será aquele que contém os preditores mais importantes (com maiores coeficientes $\beta$ ), o modelo obtido por seleção retrógrada será aquele com o maior número de preditores significantes e o obtido por seleção passo-a-passo será aquele com maior poder preditivo.

A técnica de regressão logística múltipla tem suas limitações. Um dos principais pressupostos para usar esta técnica é que as variáveis do lado direito da equação sejam realmente independentes, ou seja, que não exista associação entre elas. Se, por exemplo, chegarmos à equação 3 e em um teste de hipótese Apfel for associado com Quimioterapia com $p<0,05$ este modelo terá coeficientes $\beta$ errados. Outra limitação é que as variáveis independentes precisam ter uma relação linear com a variável dependente para que o cálculo dos coeficientes seja efetivo. 


\section{Curvas ROC}

O resultado de uma regressão logística é um número entre zero e um e este número representa a probabilidade da variável prevista. Curvas ROC (do inglês Receiver Operating Curves) ou CCO (curvas de características operacionais) são curvas que representam a relação entre sensibilidade e especificidade de acordo com um ponto de corte escolhido no resultado da equação para tomar uma decisão.

Após ser gerada a equação da regressão logística, ela é aplicada a cada um dos pacientes. Existe então para cada paciente um resultado da aplicação da regressão logística e um desfecho (variável dependente) como no exemplo da Tabela 11.

Tabela 11: exemplo de ponto de corte.

Paciente Resultado da aplicação da Desfecho (vomitou?) regressão

\begin{tabular}{lll}
\hline 1 & 0,1 & Não \\
2 & 0,2 & Não \\
3 & 0,3 & Sim \\
4 & 0,8 & Sim \\
5 & 0,9 & Sim
\end{tabular}

A próxima etapa é testar os pontos de corte. Um ponto de corte é um valor acima do qual se espera encontrar os pacientes com desfecho positivo (vomitou = sim no exemplo) e abaixo do qual espera-se encontrar o desfecho negativo (vomitou $=$ não no exemplo).

Para cada ponto de corte calcula-se sensibilidade e especificidade. Sensibilidade é a proporção dos casos positivos que encontram-se acima do ponto de corte. Por exemplo, na tabela 11 , se o ponto de corte for 0,7 então 
apenas dois dos 3 pacientes que vomitaram serão detectados (pacientes 4 e 5). A sensibilidade será portanto $66,6 \%$. A especificidade é a proporção dos pacienes com desfecho negativo que têm resultado da regressão abaixo do ponto de corte. No exemplo do ponto de corte de 0,7 a especificidade é $100 \%$ porque todos os pacientes com desfecho negativo ( 1 e 2) têm resultado da regressão abaixo de 0,7 que foi o ponto de corte testado.

Para desenhar a curva $\mathrm{ROC}$ o pacote estatístico calcula a sensibilidade e a especificidade de todos os pontos entre zero e um, um a um, como mostra a Figura 2.

Quanto mais próxima da linha de identidade (linha diagonal que divide o gráfico em exatamente 2) pior a capacidade do modelo em discriminar casos positivos e negativos. Uma curva ROC com linha abaixo da linha da identidade significa modelo gerado errado. As curvas ROC sempre têm suas linhas acima da linha da identidade.

A área abaixo das curvas ROC (AAC) sintetiza o poder de discriminação do modelo. Quanto mais próxima de 0,5 pior o poder de discriminação e quanto mais próxima de um melhor. Para cada modelo de regressão logística calculase a AAC como indicador de seu poder de discriminação. 


\section{Referências bibliográficas}

1. Watcha MF, White PF: Postoperative nausea and vomiting. Its etiology, treatment, and prevention. Anesthesiology 1992; 77: 162-184

2. Lages N, Fonseca C, Neves A, Landeiro N, Abelha FJ: [Postoperative nausea and vomiting: a review of the 'minor-major' problem.]. Rev Bras Anestesiol 2005; 55: 575-85 3. Apfel CC, Roewer N, Korttila K: How to study postoperative nausea and vomiting. Acta Anaesthesiol Scand 2002; 46: 921-928

4. Cruthirds D, Sims PJ, Louis PJ: Review and recommendations for the prevention, management, and treatment of postoperative and postdischarge nausea and vomiting. Oral surgery, oral medicine, oral pathology and oral radiology 2013; 115: 601-611

5. Thompson HJ: The management of post-operative nausea and vomiting. Journal of advanced nursing 1999; 29: 1130-1136

6. Graham JR: Understanding and Management of Nausea and Vomiting. Journal of Advanced Nursing 1995; 22: 194-194

7. Broomhead C: Physiology of postoperative nausea and vomiting. British journal of hospital medicine 1994; 53: 327-330

8. Cotton JW, Rowell LR, Hood RR, Pellegrini JE: A comparative analysis of isopropyl alcohol and ondansetron in the treatment of postoperative nausea and vomiting from the hospital setting to the home. AANA J 2007; 75: 21-26

9. Chiravalle P, McCaffrey R: Alternative therapy applications for postoperative nausea and vomiting. Holist Nurs Pract 2005; 19: 207-210

10. Apfel CC, Korttila K, Abdalla M, Kerger H, Turan A, Vedder I, Zernak C, Danner K, Jokela R, Pocock SJ, Trenkler S, Kredel M, Biedler A, Sessler DI, Roewer N, IMPACTI: A factorial trial of six interventions for the prevention of postoperative nausea and vomiting. N Engl J Med 2004; 350: 2441-2451

11. Rüsch D, Eberhart LHJ, Wallenborn J, Kranke P: Nausea and vomiting after surgery under general anesthesia: an evidence-based review concerning risk assessment, prevention, and treatment. Dtsch Arztebl Int 2010; 107: 733-741

12. Hocking G, Weightman W, Smith C, Gibbs N, Sherrard K: Measuring the quality of anaesthesia from a patient's perspective: development, validation, and implementation of a short questionnaire. British journal of anaesthesia 2013; 111: 979-989

13. Macario A, Weinger M, Carney S, Kim A: Which clinical anesthesia outcomes are important to avoid? The perspective of patients. Anesthesia \& Analgesia 1999; 89: 652

14. Apfel CC, Läärä E, Koivuranta M, Greim CA, Roewer N: A simplified risk score for predicting postoperative nausea and vomiting: conclusions from cross-validations between two centers. Anesthesiology 1999; 91: 693-700

15. Eberhart LH, Högel J, Seeling W, Staack AM, Geldner G, Georgieff M: Evaluation of three risk scores to predict postoperative nausea and vomiting. Acta Anaesthesiol Scand 2000; 44: 480-488

16. Koivuranta $\mathrm{M}$, Läärä E, Snåre L, Alahuhta S: A survey of postoperative nausea and vomiting. Anaesthesia 1997; 52: 443-449

17. Palazzo M, Evans R: Logistic regression analysis of fixed patient factors for postoperative sickness: a model for risk assessment. Br J Anaesth 1993; 70: 135-140

18. Stadler M, Bardiau F, Seidel L, Albert A, Boogaerts JG: Difference in risk factors for postoperative nausea and vomiting. Anesthesiology 2003; 98: 46-52

19. Visser K, Hassink EA, Bonsel GJ, Moen J, Kalkman CJ: Randomized controlled trial of total intravenous anesthesia with propofol versus inhalation anesthesia with 
isoflurane-nitrous oxide: postoperative nausea with vomiting and economic analysis. Anesthesiology 2001; 95: 616-626

20. Apfel CC, Kranke P, Katz MH, Goepfert C, Papenfuss T, Rauch S, Heineck R, Greim CA, Roewer N: Volatile anaesthetics may be the main cause of early but not delayed postoperative vomiting: a randomized controlled trial of factorial design. $\mathrm{Br} \mathrm{J}$ Anaesth 2002; 88: 659-668

21. Scuderi PE, Conlay LA: Postoperative nausea and vomiting and outcome. Int Anesthesiol Clin 2003; 41: 165-174

22. Watcha MF: The cost-effective management of postoperative nausea and vomiting. Anesthesiology 2000; 92: 931

23. Gan TJ, Sloan F, de L Dear G, El-Moalem HE, Lubarsky DA: How much are patients willing to pay to avoid postoperative nausea and vomiting? Anesthesia \& Analgesia 2001; 92: 393-400

24. Eberhart L, Morin A, Wulf H, Geldner G: Patient preferences for immediate postoperative recovery. British journal of anaesthesia 2002; 89: 760-761

25. Macario A, Weinger M, Carney S, Kim A: Which clinical anesthesia outcomes are important to avoid? The perspective of patients. Anesth Analg 1999; 89: 652-658

26. Tramer MR, Reynolds DJM, Moore RA, McQuay HJ: Efficacy, dose-response, and safety of ondansetron in prevention of postoperative nausea and vomiting: a quantitative systematic review of randomized placebo-controlled trials. Anesthesiology 1997; 87: 1277-1289

27. Apfel CC, Kranke P, Eberhart LHJ, Roos A, Roewer N: Comparison of predictive models for postoperative nausea and vomiting. Br J Anaesth 2002; 88: 234-240

28. Schumann R, Polaner DM: Massive subcutaneous emphysema and sudden airway compromise after postoperative vomiting. Anesthesia \& Analgesia 1999; 89: 796

29. White PF, Watcha MF: Postoperative nausea and vomiting: prophylaxis versus treatment. Anesthesia \& Analgesia 1999; 89: 1337

30. White PF, O'Hara JF, Roberson CR, Wender RH, Candiotti KA, Group P-OS: The impact of current antiemetic practices on patient outcomes: a prospective study on highrisk patients. Anesth Analg 2008; 107: 452-8

31. Gan TJ, Diemunsch P, Habib AS, Kovac A, Kranke P, Meyer TA, Watcha M, Chung F, Angus S, Apfel CC: Consensus Guidelines for the Management of Postoperative Nausea and Vomiting. Anesthesia \& Analgesia 2014; 118: 85-113

32. Apfel CC, Philip BK, Cakmakkaya OS, Shilling A, Shi Y-Y, Leslie JB, Allard M, Turan A, Windle P, Odom-Forren J: Who is at risk for postdischarge nausea and vomiting after ambulatory surgery? Anesthesiology 2012; 117: 475-486

33. Apfel CC, Läärä E, Koivuranta M, Greim CA, Roewer N: A simplified risk score for predicting postoperative nausea and vomiting: conclusions from cross-validations between two centers. Anesthesiology 1999; 91: 693-700

34. Sarin P, Urman RD, Ohno-Machado L: An improved model for predicting postoperative nausea and vomiting in ambulatory surgery patients using physicianmodifiable risk factors. Journal of the American Medical Informatics Association 2012; 19: $995-1002$

35. Graham I, Atar D, Borch-Johnsen K, Boysen G, Burell G, Cifkova R, Dallongeville J, De Backer G, Ebrahim S, Gjelsvik B: European guidelines on cardiovascular disease prevention in clinical practice: executive summary Fourth Joint Task Force of the European Society of Cardiology and Other Societies on Cardiovascular Disease Prevention in Clinical Practice (Constituted by representatives of nine societies and by invited experts). European heart journal 2007; 28: 2375-2414 
36. Qaseem A, Snow V, Barry P, Hornbake ER, Rodnick JE, Tobolic T, Ireland B, Segal JB, Bass EB, Weiss KB: Current Diagnosis of Venous Thromboembolism in Primary Care: A Clinical Practice Guideline from the American Academy of Family Physicians and the American College of Physicians*. Annals of internal medicine 2007; 146: 454-458

37. Emiliano PC, Veiga EP, Vivanco MJ, Menezs FS: Critérios de Informação de Akaike Versus Bayesiano: Análise Comparativa. 19 ${ }^{\circ}$ Simpósio Nacional de Probabilidade e Estatística 2010

38. Eberhart LH, Högel J, Seeling W, Staack AM, Geldner G, Georgieff M: Evaluation of three risk scores to predict postoperative nausea and vomiting. Acta Anaesthesiol Scand 2000; 44: 480-488

39. Thomas R, Jones NA, Strike P: The value of risks scores for predicting postoperative nausea and vomiting when used to compare patient group in a randomised controlled trial. Anaesthesia 2002; 57: 1119-1128

40. Roscoe JA, Morrow GR, Aapro MS, Molassiotis A, Olver I: Anticipatory nausea and vomiting. Supportive Care in Cancer 2011; 19: 1533-1538

41. Cohen MM, Duncan PG, DeBoer DP, Tweed WA: The postoperative interview: assessing risk factors for nausea and vomiting. Anesth Analg 1994; 78: 7-16

42. Apfel C, Greim C, Haubitz I, Goepfert C, Usadel J, Sefrin P, Roewer N: A risk score to predict the probability of postoperative vomiting in adults. Acta Anaesthesiologica Scandinavica 1998; 42: 495-501

43. Apfel C, Greim C, Haubitz I, Grundt D, Goepfert C, Sefrin P, Roewer N: The discriminating power of a risk score for postoperative vomiting in adults undergoing various types of surgery. Acta anaesthesiologica scandinavica 1998; 42: 502-509

44. Weilbach C, Rahe-Meyer N, Raymondos K, Weissig A, Scheinichen D, Piepenbrock S: Postoperative nausea and vomiting (PONV): Usefulness of the ApfelScore for identification of high risk patients for PONV. Acta Anæsthesiologica Belgica 2006; 57: 361

45. Sinclair DR, Chung F, Mezei G: Can postoperative nausea and vomiting be predicted? Anesthesiology 1999; 91: 109-118

46. Pierre S, Benais H, Pouymayou J: Apfel's simplified score may favourably predict the risk of postoperative nausea and vomiting. Can J Anaesth 2002; 49: 237-242

47. Sigaut S, Merckx P, Peuch C, Necib S, Pingeon F, Mantz J: Does an educational strategy based on systematic preoperative assessment of simplified Apfel's score decrease postoperative nausea and vomiting?, Annales francaises d'anesthesie et de reanimation, Elsevier, 2010, pp 765-769

48. Apfel C, Heidrich F, Jukar-Rao S, Jalota L, Hornuss C, Whelan R, Zhang K, Cakmakkaya O: Evidence-based analysis of risk factors for postoperative nausea and vomiting. British journal of anaesthesia 2012; 109: 742-753

49. Horn CC, Wallisch WJ, Homanics GE, Williams JP: Pathophysiological and neurochemical mechanisms of postoperative nausea and vomiting. European Journal of Pharmacology 2014; 722: 55-66

50. Chou WY, Yang LC, Lu HF, Ko JY, Wang CH, Lin SH, Lee TH, Concejero A, Hsu CJ: Association of $\mu$-opioid receptor gene polymorphism (A118G) with variations in morphine consumption for analgesia after total knee arthroplasty. Acta Anaesthesiologica Scandinavica 2006; 50: 787-792

51. Janicki PK, Vealey R, Liu J, Escajeda J, Postula M, Welker K: Genome-wide association study using pooled DNA to identify candidate markers mediating susceptibility to postoperative nausea and vomiting. Anesthesiology 2011; 115: 54-64 
52. Kolesnikov Y, Gabovits B, Levin A, Voiko E, Veske A: Combined catechol-Omethyltransferase and $\mu$-opioid receptor gene polymorphisms affect morphine postoperative analgesia and central side effects. Anesthesia \& Analgesia 2011; 112: 448453

53. Laugsand EA, Fladvad T, Skorpen F, Maltoni M, Kaasa S, Fayers P, Klepstad P: Clinical and genetic factors associated with nausea and vomiting in cancer patients receiving opioids. European Journal of Cancer 2011; 47: 1682-1691

54. Pang GSY, Ithnin F, Wong YY, Wang JB, Lim Y, Sia ATH, Lee CGL: A nonsynonymous single nucleotide polymorphism in an OPRM1 splice variant is associated with fentanyl-induced emesis in women undergoing minor gynaecological surgery. PloS one 2012; 7: e48416

55. Rueffert H, Thieme V, Wallenborn J, Lemnitz N, Bergmann A, Rudlof K, Wehner M, Olthoff D, Kaisers UX: Do variations in the 5-HT3A and 5-HT3B serotonin receptor genes (HTR3A and HTR3B) influence the occurrence of postoperative vomiting? Anesthesia \& Analgesia 2009; 109: 1442-1447

56. Sia AT, Lim Y, Lim EC, Goh RW, Law HY, Landau R, Teo Y-y, Tan EC: A118G single nucleotide polymorphism of human [mu]-opioid receptor gene influences pain perception and patient-controlled intravenous morphine consumption after intrathecal morphine for postcesarean analgesia. Anesthesiology 2008; 109: 520-526

57. Zhang W, Yuan J, Kan Q, Zhang L, Chang Y, Wang Z: Study of the OPRM1 A118G genetic polymorphism associated with postoperative nausea and vomiting induced by fentanyl intravenous analgesia. Minerva anestesiologica 2011; 77: 33-39

58. Nakagawa M, Kuri M, Kambara N, Tanigami H, Tanaka H, Kishi Y, Hamajima $\mathrm{N}$ : Dopamine D2 receptor Taq IA polymorphism is associated with postoperative nausea and vomiting. Journal of anesthesia 2008; 22: 397-403

59. Beleslin D, Štrbac M: Noradrenaline-induced emesis: alpha-2 adrenoceptor mediation in the area postrema. Neuropharmacology 1987; 26: 1157-1165

60. Hikasa Y, Ogasawara S, Takase K: Alpha adrenoceptor subtypes involved in the emetic action in dogs. Journal of Pharmacology and Experimental Therapeutics 1992; 261: 746-754

61. Robin X, Turck N, Hainard A, Tiberti N, Lisacek F, Sanchez J-C, Müller M: pROC: an open-source package for $\mathrm{R}$ and $\mathrm{S}+$ to analyze and compare ROC curves. BMC bioinformatics 2011; 12: 77

62. DeLong ER, DeLong DM, Clarke-Pearson DL: Comparing the areas under two or more correlated receiver operating characteristic curves: a nonparametric approach. Biometrics 1988; 44: 837-845

63. Kranke P, Eberhart LH: Possibilities and limitations in the pharmacological management of postoperative nausea and vomiting. Eur J Anaesthesiol 2011; 28: 758-65 64. Gigerenzer G, Gaissmaier W: Heuristic decision making. Annu Rev Psychol 2011; 62: 451-482

65. Peng SY, Wu KC, Wang JJ, Chuang JH, Peng SK, Lai YH: Predicting postoperative nausea and vomiting with the application of an artificial neural network. $\mathrm{Br}$ J Anaesth 2007; 98: 60-65

66. Wilder-Smith $\mathrm{OH}$, Martin NC, Morabia A: Postoperative nausea and vomiting: a comparative survey of the attitudes, perceptions, and practice of Swiss anesthesiologists and surgeons. Anesthesia \& Analgesia 1997; 84: 826-831

67. Kappen T, Vergouwe Y, van Wolfswinkel L, Kalkman C, Moons K, van Klei W: Impact of adding therapeutic recommendations to risk assessments from a prediction 
model for postoperative nausea and vomiting. British journal of anaesthesia $2015 ; 114$ : $252-260$

68. Kappen TH, Moons KG, Van Wolfswinkel L, Kalkman CJ, Vergouwe Y, Van Klei WA: Impact of risk assessments on prophylactic antiemetic prescription and the incidence of postoperative nausea and vomiting: a cluster-randomized trial. Survey of Anesthesiology 2014; 58: 245-246

69. Charbit B, Albaladejo P, Funck-Brentano C, Legrand M, Samain E, Marty J: Prolongation of QTc interval after postoperative nausea and vomiting treatment by droperidol or ondansetron. Anesthesiology-Hagerstown 2005; 102: 1094-1100

70. Chandrakala R, Vijayashankara C, Kumar KK, Sarala N: Ondansetron induced fatal ventricular tachycardia. Indian journal of pharmacology 2008; 40: 186

71. Afonso N, Dang A, Namshikar V, Kamat S, Rataboli PV: Intravenous ondansetron causing severe bradycardia: two cases. Annals of cardiac anaesthesia 2009; 12: 170

72. Apfel CC, Korttila K, Abdalla M, Kerger H, Turan A, Vedder I, Zernak C, Danner K, Jokela R, Pocock SJ, Trenkler S, Kredel M, Biedler A, Sessler DI, Roewer N, Investigators I: A factorial trial of six interventions for the prevention of postoperative nausea and vomiting. N Engl J Med 2004; 350: 2441-51

73. Okoli G, Sanders R, Myles P: Demystifying propensity scores. British journal of anaesthesia 2014; 112: 13-15

74. Gan TJ: Risk factors for postoperative nausea and vomiting. Anesthesia \& Analgesia 2006; 102: 1884-1898

75. Hesketh PJ: Chemotherapy-induced nausea and vomiting. N Engl J Med 2008; 358: 2482-94

76. Fasching P, Kollmannsberger B, Strissel P, Niesler B, Engel J, Kreis H, Lux M, Weihbrecht S, Lausen B, Bani M: Polymorphisms in the novel serotonin receptor subunit gene HTR3C show different risks for acute chemotherapy-induced vomiting after anthracycline chemotherapy. Journal of cancer research and clinical oncology 2008; 134 : 1079-1086

77. Oddby-Muhrbeck E, Öbrink E, Eksborg S, Rotstein S, Lönnqvist P: Is there an association between PONV and chemotherapy-induced nausea and vomiting? Acta Anaesthesiologica Scandinavica 2013

78. Morrow G, Rosenthal S: Models, mechanisms and management of anticipatory nausea and emesis. Oncology 1996; 53: 4-7

79. Morrow GR, Roscoe JA, Kirshner JJ, Hynes HE, Rosenbluth RJ: Anticipatory nausea and vomiting in the era of 5-HT3 antiemetics. Supportive care in cancer 1998; 6: 244-247

80. Aapro MS, Molassiotis A, Olver I: Anticipatory nausea and vomiting. Supportive care in cancer $2005 ; 13: 117-121$ 


\section{Apêndice: publicação decorrente desta tese}

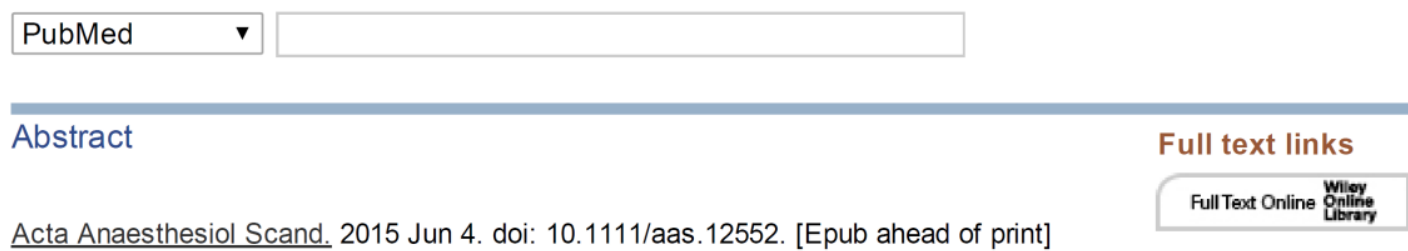

\section{Does previous chemotherapy-induced nausea and vomiting predict postoperative nausea and vomiting?}

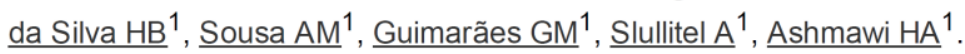

\section{Author information}

\section{Abstract}

BACKGROUND: Postoperative nausea and vomiting (PONV) remains a problem in the postoperative period. Previous PONV in oncology patients has recently been associated with chemotherapy-induced nausea and vomiting (CINV). We assessed if CINV could improve Apfel's heuristic for predicting PONV.

METHODS: We conducted a retrospective study of 1500 consecutive patients undergoing intermediate or major cancer surgery between April and July 2011. PONV was assessed in the first postoperative day during post-anaesthesia care. The assigned anaesthetist completed an electronic medical record with all of the studied variables. Multiple logistic regression analyses were performed to assess whether any of the variables could add predictive ability to Apfel's tallying heuristic, and receiver operating characteristic $(R O C)$ curves were modelled. The areas under the curve (AUC) were used to compare the model's discriminating ability for predicting patients who vomited from those who did not vomit.

RESULTS: The overall incidence of PONV was $26 \%$. Multiple logistic regressions identified two independent predictors for PONV (odds ratio; 95\% Cl), Apfel's score (1.78; 1.23-2.63) and previous chemotherapy-induced vomiting $(3.15 ; 1.71-5.9)$, Hosmer-Lemeshow's $P<0.0001$. Previous CINV was the most significant predictor to be added to Apfel's heuristic in this population.

CONCLUSIONS: A history of chemotherapy-induced nausea vomiting was a strong predictor for PONV and should be investigated as an added risk factor for PONV in the preoperative period of oncology surgery in prospective studies.

() 2015 The Acta Anaesthesiologica Scandinavica Foundation. Published by John Wiley \& Sons Ltd. 